\title{
Modulating the innate immune response to influenza $A$ virus: potential therapeutic use of anti-inflammatory drugs
}

\author{
Irene Ramos* and Ana Fernandez-Sesma* \\ Department of Microbiology, Icahn School of Medicine at Mount Sinai, New York, NY, USA
}

OPEN ACCESS

Edited by:

Shakti Singh,

University of Alberta, Canada

Reviewed by:

Andrea Sant

David H. Smith Center for Vaccine

Biology and Immunology, USA

Paul G. Thomas,

St. Jude Children's Research

Hospital, USA

Stacey Schultz-Cherry,

St Jude Children's Research Hospital, USA

*Correspondence:

Irene Ramos and

Ana Fernandez-Sesma,

Department of Microbiology, Icahn School of Medicine at Mount Sinai,

1468 Madison Avenue, New York, NY 10029, USA

irene.ramos-lopez@mssm.edu:

ana.sesma@mssm.edu

Specialty section:

This article was submitted to

Immunotherapies and Vaccines,

a section of the journal

Frontiers in Immunology

Received: 21 April 2015

Accepted: 04 July 2015

Published: 20 July 2015

Citation:

Ramos I and Fernandez-Sesma A (2015) Modulating the innate immune response to influenza $A$ virus: potential therapeutic use of

anti-inflammatory drugs.

Front. Immunol. 6:361.

doi: 10.3389/fimmu.2015.00361
Infection by influenza A viruses (IAV) is frequently characterized by robust inflammation that is usually more pronounced in the case of avian influenza. It is becoming clearer that the morbidity and pathogenesis caused by IAV are consequences of this inflammatory response, with several components of the innate immune system acting as the main players. It has been postulated that using a therapeutic approach to limit the innate immune response in combination with antiviral drugs has the potential to diminish symptoms and tissue damage caused by IAV infection. Indeed, some anti-inflammatory agents have been shown to be effective in animal models in reducing IAV pathology as a proof of principle. The main challenge in developing such therapies is to selectively modulate signaling pathways that contribute to lung injury while maintaining the ability of the host cells to mount an antiviral response to control virus replication. However, the dissection of those pathways is very complex given the numerous components regulated by the same factors (i.e., NF kappa B transcription factors) and the large number of players involved in this regulation, some of which may be undescribed or unknown. This article provides a comprehensive review of the current knowledge regarding the innate immune responses associated with tissue damage by IAV infection, the understanding of which is essential for the development of effective immunomodulatory drugs. Furthermore, we summarize the recent advances on the development and evaluation of such drugs as well as the lessons learned from those studies.

Keywords: influenza virus, inflammation, innate immunity, ARDS, cytokines, anti-inflammatory therapy

\section{Introduction}

Influenza A virus (IAV) infection usually results in a mild and self-limiting disease that in some individuals, commonly those with underlying medical conditions, can result in complications leading to severe disease and death. Pneumonia, bronchitis, sinus infections, and ear infections are examples of influenza-related complications (1). Thus, influenza has a significant economic impact and is a very important public health concern, with a rate for the 2014-2015 season of 57.1 laboratory-confirmed influenza-associated hospitalizations per 100,000 people reported as of March 14th, 2015 (2). The highest rate of hospitalization is among adults over 65 years old, followed by children under 4 years old, and the average annual influenza-associated deaths in the United States from 1976 to 2007 are 23,607 (3). 
Characteristics of the IAV genome, such as its negative-sense, single-stranded segmented RNA, and its airborne transmission in humans provides this virus with a great pandemic potential. The co-circulation of different subtypes in animal reservoirs leads to reassortment (antigenic shift), which may result in a novel subtype that is able to transmit to the human population (4). The circulating IAV subtypes in humans as of 2015 are H1N1 viruses, which caused a pandemic in 2009 , and H3N2 viruses; however, several different subtypes have circulated in humans during the last century. The natural hosts of IAV are aquatic birds, which may sporadically transmit viruses to poultry. Humans are, on occasion, infected by these viruses, causing what is known as avian influenza, which is associated with severe disease and high fatality rates $(5,6)$. The human-to-human transmission in these cases is very limited, and the most important of these IAV are the H5N1 and H7N9 subtypes.

Uncomplicated cases of influenza are limited to attachment and viral replication in the upper respiratory tract, and the symptoms in these cases are nasal obstruction, cough, sore throat, headache, fever, chills, anorexia, and myalgia. These symptoms are the consequences of the inflammation induced upon viral infection (7). Complications of IAV infection are more frequent in people with underlying comorbidities, such as chronic pulmonary or cardiac disease, asthma, immunosuppression, or diabetes mellitus. These complications begin when the viral infection reaches the alveolar epithelium in the lower respiratory tract, where severe tissue damage may occur and affect gas exchange. In alveolar tissue, type I pneumocytes prevent fluid leakage across the alveolar-capillary barrier, and type II pneumocytes resorb fluid from the alveolar lumen and produce lung surfactant (8). Thus, damage of the alveolar epithelium leads to respiratory dysfunction or acute respiratory distress syndrome (ARDS), which often occurs in cases of severe influenza. More extensive discussion on the contribution of the different cell types to tissue damage during influenza infection has been recently published in a very interesting review (9). Most of the lung pathology during influenza virus-induced ARDS is associated with the release of cytokines and other pro-inflammatory mediators, and the contribution of the direct viral cytopathic effect to the alveolar damage is still unclear $(10,11)$. H5N1 viruses have also been reported to spread to extra-respiratory tissue, although with limited or no viral replication (12).

Influenza complications are also frequently associated with secondary bacterial infections, which may be explained by a series of changes that the virus induces in the lung epithelial cells of the host that predisposes to adherence and invasion as well as changes in the immune response (13-15). For example, it is believed that IAV infection upregulates CD200 receptor in lung myeloid cells, which is involved in negative immune regulation upon interaction with the ligand CD200, resulting in predisposition to secondary bacterial infection (16).

Disease severity caused by IAV infection is greatly associated with high levels of inflammation, with increasing evidence that tissue damage is produced by an exaggerated innate immune response. Thus, many researchers have proposed that treatment with anti-inflammatory therapy could be beneficial. The primary challenge to successfully establish this type of therapy is to downregulate specific mediators of the immune system that have a detrimental effect while avoiding increased levels of viral replication. Here, a review of the innate immunity processes associated with severe cases of IAV infection is provided. Specifically, we discuss clinical studies that have been published regarding the cytokines and chemokines shown to be upregulated in serum or lung tissue of patients with severe disease. We also provide a brief review of the most frequent of those immune mediators, including signaling pathways activated by them and the cellular processes that might lead to tissue damage and disease progression. Finally, anti-inflammatory therapies that have been proposed and tested, either in clinical, preclinical, or in vitro studies, are also discussed.

\section{Innate Immunity to IAV}

The first barrier that IAV encounters when invading the host is the mucus layer covering the respiratory and oral epithelia. If the virus successfully overcomes this barrier, it can bind the respiratory epithelial cells, be internalized, and start replicating (17). The cellular defense mechanisms that are initiated upon pathogen invasion involve the sensing of components of pathogens, or pathogen-associated molecular patterns (PAMPs), by patternrecognition receptors (PRRs) in host cells. This recognition leads to activation of subsequent signaling events that result in the secretion of inflammatory cytokines, type I interferon (IFN), chemokines, and antimicrobial peptides. There are several types of PRRs with a cell-type specific distribution and sub-cellular localizations that may be cytoplasmic, endosomal, or in the plasma membrane.

Cytoplasmic receptors include the retinoic acid-inducible gene I (RIG-I)-like receptors (RLRs), the nucleotide oligomerization domain (NOD)-like receptors (NLRs), and the less-characterized cytosolic DNA sensors (18). These receptors are particularly important in the context of viral infection. Within the RLR family, the most important proteins are RIG-I, melanoma differentiation factor 5 (MDA5), and laboratory of genetics and physiology 2 (LGP2), all of which are expressed in the cytosol of most cell types and participate in the recognition of single-stranded and doublestranded RNA (19). The most studied of the NLRs in the context of virus infection is the NLR family pyrin domain containing 3 (NLRP3), which upon stimulation leads to the activation of the inflammasome system, with important implications in inflammation (20). NLRP3 is expressed in myeloid cell types, such as monocytes, macrophages, dendritic cells (DCs), and neutrophils and in lung epithelial cells (21). Several PAMPs and damageassociated molecular patterns (DAMPs) have been proposed to activate this receptor, including dsRNA (22), the M2 protein of influenza virus (23), and reactive oxygen species (ROS) (24).

Another very important family of PRRs is the toll-like receptors (TLRs). Some of these receptors, such as TLR1, TLR2, TLR4, TLR5, and TLR6, are located in the plasma membrane and are activated mainly by lipids, lipoprotein, and proteins. Other TLRs, namely, TLR3, TLR7, TLR8, and TLR9, are expressed in endosomal compartments and recognize nucleic acids (25). TLRs are highly expressed in antigen-presenting cells, such as DCs and macrophages, and they are also known to be expressed in several $\mathrm{T}$ cell subsets (26). For IAV and other RNA viruses, the most 
important of these TLRs are TLR3 and TLR7/8, which recognize dsRNA and ssRNA, respectively (27).

Other PRRs that are expressed on the cell surface of antigenpresenting cells are the C-type lectin receptors (CLRs), such as the DC-specific intercellular adhesion molecule-3-grabbing nonintegrin (DC-SIGN) or dectin-1 and dectin-2. CLRs recognize carbohydrate ligands and are also mainly expressed in antigenpresenting cells (28). Several reports have shown an interaction between IAV and DC-SIGN (29-31), which would facilitate infection of DCs.

Recognition of PAMPs by these PRRs leads to the activation of multiple signaling cascades initiating the innate immune response. This response leads to the production of type I and type III IFNs. Binding of these IFNs to their receptors in a paracrine or autocrine manner leads to the establishment of an antiviral response, characterized by the expression of hundreds of genes that will counteract viral replication (32). Also, PAMP sensing results in the release of pro-inflammatory cytokines and chemokines by the cells that will contribute to the development and modulation of specific $T$ cell responses and recruitment of different immune cells, such as monocytes, neutrophils, and natural killer (NK) cells, to the infected tissue. In the case of antigenpresenting cells, such as DCs and some subtypes of macrophages, they also undergo maturation and migrate to the secondary lymphoid organs where antigen is presented to T (33) and B cells (34). These adaptive immune responses initiated upon innate immune activation are known to be necessary for protection and viral clearance, as recently reviewed by Chiu and Openshaw (35).

Hence, in the current model of IAV-induced ARDS, IAV particles invade a new host and if, able to cross the mucosal barrier, will infect tissue cells in the upper respiratory tract. In some cases, the virus reaches the lung, where it can infect type I and II pneumocytes, endothelial cells, and immune cells (9, 36-38). The presence of the virus is detected by infected cells, which release cytokines, chemokines, and other mediators in order to control the infection and remove dead cells and stimulate the initiation of adaptive immune responses. However, other effects of those mediators, which are described in detail below, are detrimental for the integrity of the tissue $(11,39)$.

While these alert systems are aimed to mount an effective immune response to clear viral infection, there are also important negative consequences of those responses that might compromise tissue integrity. One of the most described of those consequences is the production of ROS. Pro-inflammatory mediators induce intracellular ROS by activating the nicotinamide adenine dinucleotide phosphate (NADPH) oxidase activity. Also, work by Ye et al. has shown that inhibiting ROS production in vitro results in attenuation of release of pro-inflammatory cytokines $(40,41)$, thereby amplifying the immune response. In addition to reacting with DNA, proteins, and lipids resulting in structural cell and tissue damage, ROS are known to be the second messengers that participate in several signaling pathways and function as transcriptional regulators (42). It is also known that pro-inflammatory responses activate signaling pathways that result in the activation of apoptosis and necrosis $(43,44)$. Accordingly, apoptotic alveolar epithelial cells have been observed by histochemistry of lung tissue from two patients who died by H5N1 infection (12).

\section{Hypercytokinemia and Pathogenesis in Severe Cases of Human Influenza}

Several studies have characterized the profile of cytokines in human cases of influenza in order to understand the connection between innate immunity and pathogenesis. In cases of seasonal influenza, complications are mostly associated with secondary bacterial infection. Most cases of severe primary viral pneumonia have been associated with pandemic influenza, such as $2009 \mathrm{H} 1 \mathrm{~N} 1$ or $1918 \mathrm{H} 1 \mathrm{~N} 1$ influenza virus, and cases of avian influenza, such as infections by $\mathrm{H} 5 \mathrm{~N} 1$ or H7N9 influenza viruses $(45,46)$.

Acute respiratory distress syndrome is the main cause of death in IAV-infected patients $(47,48)$. Histopathology caused by complicated IAV infection in the absence of bacterial pneumonia consists of inflammation, congestion, epithelial necrosis of the larger airways, and diffuse alveolar damage characterized by hyaline membranes, interstitial and intra-alveolar edema, necrotizing bronchitis and bronchiolitis, and in some cases, hemorrhage (49, 50). Autopsies from fatal cases of $1918 \mathrm{H} 1 \mathrm{~N} 1, \mathrm{H} 5 \mathrm{~N} 1$, and the 2009 H1N1 pandemic virus show comparable pathological characteristics $(47,50)$. Fatal infection with H7N9 influenza viruses in humans also showed diffuse alveolar damage as one of the main histopathology findings (51).

The majority of the patients infected by pandemic $2009 \mathrm{H} 1 \mathrm{~N} 1$ virus experienced a mild disease with influenza-like symptoms that typically resolved in a few weeks $(47,48)$. However, due to the lack of pre-existing immunity against this virus, complications of the disease occurred in some patients, mostly those with underlying conditions (47). Gao et al. found the levels of seven proteins markedly upregulated in lung tissue in fatal cases of influenza virus $2009 \mathrm{H} 1 \mathrm{~N} 1$ infection. Those proteins are interleukin (IL)1 receptor antagonist protein (IL1RA), IL6, tumor necrosis factor (TNF)- $\alpha$, IL8, monocyte chemoattractant protein 1 (MCP1), macrophage inflammatory protein (MIP) $1 \beta$, and IFN $\gamma$-inducible protein-10 (IP10)(52). In this work, they also found high levels of apoptosis in the lungs and airway by terminal deoxynucleotidyl transferase dUTP nick end labeling (TUNEL) staining, as well as marked levels of cleaved caspase 3 (52). A similar study by To et al. showed significantly higher levels of granulocyte colonystimulating factor (G-CSF), IFN $\alpha 2$, IL1 $\alpha$, IL6, IL8, IL10, IL15, IP10, and MCP1 in plasma samples of patients that developed ARDS and died than in those patients that developed mild disease at early times after onset of symptoms (48). High levels of IP10, MCP1, and MIP1 $\beta$ were also found in a separate group of patients infected by $2009 \mathrm{H} 1 \mathrm{~N} 1$ influenza virus (53). In this study, elevated levels of IL8, IL9, IL17, IL6, TNF $\alpha$, IL15, and IL12p70 were found specifically in patients that required hospitalization, and IL6, IL15, and IL12 were markers of severe disease. In agreement, other studies reported high levels of IL6, IL8, IL10, and the chemokine MCP1 in $2009 \mathrm{H} 1 \mathrm{~N} 1$ virus-infected patients (54) and correlated serum levels of IL6 and IL1 $\beta$ with disease severity in children infected by the same virus (55). An additional report showed elevated levels of IL2, IL12, IL6, IL10, IL17, and IL23 in patients with severe disease and correlation between clinical manifestations and IL6 and IL10 serum levels in patients infected by 2009 H1N1 IAV (56). Other studies reporting similar results are summarized in Table $1(54,57,58)$. 
TABLE 1 | Cytokines and chemokines detected in serum or lung tissue samples of human subjects with severe disease infected by IAV.

\begin{tabular}{|c|c|c|c|}
\hline IAV subtype & Cytokines & Chemokines & Reference \\
\hline $2009 \mathrm{H} 1 \mathrm{~N} 1$ & $\begin{array}{l}\text { IL6, TNF } \alpha, \text { IL9, IL17, } \\
\text { IL15, and IL12 }\end{array}$ & IL8 & (53) \\
\hline $2009 \mathrm{H}_{1} \mathrm{~N} 1$ & $\begin{array}{l}\text { IFN } \alpha 2, \operatorname{IL} 1 \alpha, \operatorname{IL} 6, \mathrm{IL} 10 \text {, } \\
\text { and IL15 }\end{array}$ & IL8, IP10, and MCP1 & $(48)$ \\
\hline $2009 \mathrm{H} 1 \mathrm{~N} 1$ & IL6, TNF $\alpha$, and IL15 & IL8 & $(57)$ \\
\hline $2009 \mathrm{H} 1 \mathrm{~N} 1$ & $\begin{array}{l}\text { IL2, IL12, IL6, IL10, } \\
\text { IL17, and IL23 }\end{array}$ & & $(56)$ \\
\hline $2009 \mathrm{H} 1 \mathrm{~N} 1$ & IL6 and TNF $\alpha$ & $\begin{array}{l}\text { IL8, IP10, MCP1, and } \\
\text { MIP1 } \beta\end{array}$ & $(52)$ \\
\hline 2009 H1N1 & IL6 and IL1b & & $(55)$ \\
\hline $2009 \mathrm{H} 1 \mathrm{~N} 1$ & IL6 and IL10 & IL8 and MCP1 & (54) \\
\hline $\mathrm{H} 3 \mathrm{~N} 2$ & IL6, TNF $\alpha$, and IL33 & & $(58)$ \\
\hline $\mathrm{H} 5 \mathrm{~N} 1$ & & IP10 and MIG & (59) \\
\hline $\mathrm{H} 5 \mathrm{~N} 1$ & IL6, IL10, IFN $\gamma$ & IL8, IP10, MCP1, and MIG & $(60)$ \\
\hline H5N1 & $\begin{array}{l}\text { IFN } \beta \text {, IL6, IFN } \gamma \text {, and } \\
\text { TNF } \alpha\end{array}$ & $\begin{array}{l}\text { IL8, IP10, MCP1, } \\
\text { RANTES, MIP1 } \alpha \text {, and } \\
\text { MIG }\end{array}$ & $(61)$ \\
\hline H7N9 & IL6 & IL8 and MIP1 $\beta$ & (62) \\
\hline H7N9 & IL6 & IL8 and MIP1 $\beta$ & (63) \\
\hline
\end{tabular}

Cytokine responses in H5N1-infected patients have also been studied. Peiris et al. found elevated levels of IP10 and monokine induced by IFN $\gamma$ (MIG) in serum of H5N1-infected patients (59). Similarly, de Jong et al. found the levels of IP-10, MIG, and MCP1 elevated in patients with $\mathrm{H} 5 \mathrm{~N} 1$ infections (60). Interestingly, in both studies, they found large numbers of macrophages infiltrated in the lung, in accordance with the functions of those chemokines. de Jong et al. also found elevated levels of IL6, IL8, IL10, and IFN $\gamma$ in those patients (60). The level of cytokines was associated with elevated levels of viral replication. Another study that evaluated the levels of cytokines in two fatal cases of H5N1 infection found high levels of regulated on activation, normal $\mathrm{T}$ cell expressed and secreted (RANTES), MCP1, MIP1 $\alpha$, IP10, IL8, MIG, IFN $\beta$, IL6, IFN $\gamma$, and TNF $\alpha$ in the lungs and serum in one patient, while no cytokine expression was detected in the other case (61). However, the patient who did not show cytokine expression was pregnant and treatment with glucocorticoids was provided in both cases, which may have affected the immune response although it is unclear how these or other factors could have affected the results (61).

Information regarding H7N9 IAV infections in humans is more limited given the recentness of the outbreak. However, a study evaluating the cytokine responses in infected patients identified early high levels of IL6, IL8, and MIP1 $\beta$ in serum as predictive parameters of severe or fatal outcome (62). Another study found a positive correlation of the same molecules (IL6, IL8, and MIP1 $\beta$ ) with pharyngeal virus load in H7N9-infected patients (63).

Most of these studies with human samples point to elevated levels of cytokines and chemokines in IAV-infected patients. Interestingly, there is a clear overlap in the cytokines that are observed in most of those studies. A summary of the cytokines and chemokines found to be upregulated in humans infected by IAV is provided in Table 1. Experiments performed in vitro also have identified the production of similar cytokines in different systems, including IL6, TNF $\alpha$, IFNs, IL1 $\beta$, RANTES, IL8, MIP1 $\beta$, and $\operatorname{MCP} 1(64,65)$. Since the reported data indicate that the induction of these molecules might be associated with pathogenesis, understanding the effects of those proteins in receptor-expressing cells and the signaling pathways that they induce is important for eventually translating that information to the identification of efficient and safe treatment alternatives. Therefore, in the next section, we focus on the functions of each one of those cytokines and chemokines in more detail, as well as their participation in tissue damage in other diseases or other models as an additional indicator of their pathogenic potential.

\section{Cytokines and Chemokines with Increased Expression During Severe Influenza: How They Work and Their Involvement in Tissue Damage}

Upon influenza infection, viral PAMPs are sensed by the cells and multiple signaling pathways are activated as a part of the innate immune response. The purpose of the innate immune response is to lead to the clearance of viruses and infected cells, as well as the activation of the adaptive immune response. However, these events can also result in tissue destruction as a consequence of excessive activation. Data discussed in the previous section indicate an association between the activation of the innate immune response, typically measured as the production of cytokines and chemokines in serum, and a more severe pathogenesis or fatality in many cases, supporting the hypothesis of causative relationship between innate immunity and severe disease. To provide deeper insights into these events and their connection, in this section we will review the effects and signaling pathways associated with the production of the main cytokines upregulated during influenza infection. Because of the broad and numerous functions of these cytokines, it is a challenging task to parse their functions as many of them are redundant and regulated by complex networks involving multiple transcription factors, adaptors, or secondary mediators. In terms of their potential as therapeutic targets, some therapies using monoclonal antibodies to neutralize the damaging effects of those proteins have been developed and are already in the clinic for treatment of anti-inflammatory diseases, while other approaches, such as administration of pro-inflammatory cytokines, small molecules, siRNA or shRNA, or gene therapy, are under study (66).

\section{Cytokines \\ $\mathrm{TNF} \alpha$}

TNF $\alpha$ is the most studied of the cytokines, since it is involved in a large number of functions with multiple effects, such as activation of inflammatory responses, stimulation of adaptive immunity, cell survival, apoptosis, proliferation, and cell differentiation $(67,68)$.

The receptors for TNF $\alpha$ are TNF-R1, which is constitutively expressed in most cell types, and TNF-R2, which is expressed in immune cells (67). Binding of TNF $\alpha$ to its receptor results in the activation of multiple intracellular signaling pathways, which have been extensively reviewed elsewhere $(68,69)$. Therefore, in this review, we provide a general overview of these processes and the related outcomes in terms of tissue damage and pathogenesis. 
TNF $\alpha$ leads to the activation of nuclear factor kappa-lightchain-enhancer of activated B cells (NF- $\mathrm{KB}$ ) pathway, which promotes the expression of a large number of inflammatory genes. In the classical NF- $\kappa \mathrm{B}$ pathway, which is the one activated upon TNF $\alpha$ engagement, NF- $\kappa \beta$ is a dimer made up of two subunits, p50 and p65. In a resting state, NF- $\kappa \mathrm{B}$ is inactive in the cytoplasm, forming a complex with the inhibitor of nuclear factor $\kappa \mathrm{B}(\mathrm{I} \kappa \mathrm{B})$. Stimulation that activates the pathway results in the degradation of $I \kappa B$, allowing the p50/p65 dimer to translocate to the nucleus where it interacts with DNA, leading to the regulation of gene expression (70). Other stimuli that activate NF$\kappa \mathrm{B}$ transcription factors are viral genomic RNA or DNA, bacterial products, acidic $\mathrm{pH}$, and stress-related molecules, such as ROS among others. In addition, it is known that endogenous or host-derived ligands that are generated during tissue damage are also sensed by cell surface receptors, leading to NF- $\kappa \mathrm{B}$ activation (71).

Engagement of TNF $\alpha$ to its receptor also leads to the induction of apoptosis. This occurs by several mechanisms, but the major one involves recruitment of pro-caspase 8 to TNF-R1 through the adaptors fas-associated death domain (FADD) and the TNF-R superfamily member $1 \mathrm{~A}$ (TNFRSF1A)-associated death domain (TRADD), which leads to the auto-cleavage of caspase 8 to its active form. These events then result in caspase 3 activation and induction of apoptosis. Caspase 8 also leads to the release of cytochrome $c$ from the mitochondria, contributing to apoptosis induction through the "intrinsic pathway" $(68,72)$. Interestingly, TNF $\alpha$ also induces caspase-independent cell death by a mechanism involving receptor-interacting serine/threonineprotein kinase 1 (RIPK1) by a kinase-regulated process, and it is known as necroptosis (73-75).

Another described function for $\mathrm{TNF} \alpha$ is to stimulate the production of $\operatorname{ROS}(73,74,76)$, which are also inducers of apoptosis and necrosis (76). In addition, TNF signaling stimulates the activity of the NADPH oxidases (Nox) in neutrophils and macrophages, such as NOX2, resulting in the generation of superoxide $\left(\mathrm{O}_{2}^{-}\right)(77,78)$, which is important for clearing intracellular microorganisms $(74,79)$.

On the other hand, TNF $\alpha$ signaling leads to activation of the c-jun NH2-terminal kinase (JNK) that also regulates several cellular functions including apoptosis, survival, and cell growth by phosphorylating downstream transcription factors, such as cjun, activating transcription factor 2 (ATF2), or nuclear factor of activated $\mathrm{T}$ cells (NFAT). Interestingly, ROS has also been shown to be a co-activator of TNF-induced JNK activation and cell death (76).

Given the multiple functions of TNF $\alpha$ in inflammation and tissue damage, it is a very important target for immunomodulatory therapy in general. Indeed, antibodies that block its function are used as a primary treatment in some autoimmune disorders, such as rheumatoid arthritis (RA) and Crohn's disease, and several blocking agents are already approved and used in the clinic for such disorders (80). In the case of influenza disease, TNF $\alpha$-blocking agents have also been tested for treatment of IAVinduced inflammation. Mice treated with one of these agents, etanercept, showed reduced lung inflammation and morbidity after challenge with influenza virus (81).

\section{IL6}

IL6 has been attributed to both pro-inflammatory and antiinflammatory effects $(82,83)$. In addition, IL6 is involved in the regulation of metabolism, bone homeostasis, and neural processes. The production of IL6 is tightly regulated, and its continuous production has been associated with numerous chronic and autoimmune diseases. The synthesis of this cytokine is upregulated during infection or stress, and its major roles involve the production of acute phase proteins by hepatocytes and stimulation of the adaptive response by inducing the differentiation of activated B cells and CD4 ${ }^{+} \mathrm{T}$ cells (84).

Activation of IL6 signaling may take place through classic or trans-signaling pathways. In the classical activation, IL6 interacts with membrane-bound IL6 $\alpha$-receptor (IL6R), while in the trans-activation pathway, IL6R is soluble. In both scenarios, the signal-transducing $\beta$-subunit glycoprotein gp130 forms part of the receptor complex and plays a fundamental role in initiating the signal. IL6R is expressed in a limited number of cells types, namely macrophages, neutrophils, some types of T-cells, and hepatocytes (85). However, gp130 is ubiquitously expressed, allowing IL6 signaling to take place in a broad range of tissues. It is believed that trans-signaling accounts for the pro-inflammatory effects of IL6, while the classic signaling is more associated with antiinflammatory effects. Therefore, this dual activity has interesting implications when considering IL6/IL6R as a therapeutic target. A very interesting review by Scheller et al. discusses the dual functionality of classic versus trans-signaling (83).

Dimerization of gp130 leads to Janus kinases (JAK) activation, which results in phosphorylation of tyrosine residues in the cytoplasmic region of gp130. Next, the signal transducer and activator of transcription (STAT) 3 is phosphorylated, dimerizes, and translocates to the nucleus to regulate the expression of multiple genes associated with the induction of cell growth, differentiation, and survival (86). On the other hand, phosphatase Src homology domains containing tyrosine phosphatase (SHP)2 are recruited, leading to activation of the mitogen-activated protein kinase (MAPK) pathway, including ERK1/2 (associated with survival), p38, and JNK (associated with stress). IL6 can also lead to the activation of phosphatidylinositol-4,5-bisphosphate 3-kinase (PI3K) (87), which is classically associated with survival and cell growth. An important group of genes that are also regulated by JAK/STAT3 IL6-mediated activation is the suppressor of cytokine signaling (SOCS) family. Specifically, SOCS1 and 3, which are the most related with IL6 activation, inhibit the phosphorylation of gp130, resulting in a blockade of the JAK/STAT pathway (86).

Primarily, IL6 (but also IL $1 \alpha / \beta$ and TNF $\alpha$ ) is a potent inducer of the synthesis and release of approximately 30 proteins known as the acute phase proteins $(88,89)$. Acute phase proteins are secreted mainly by hepatocytes, and have multiple immunomodulatory effects. These proteins include the C-reactive protein (CRP), serum amyloid $\mathrm{P}$ component (SAP), mannose-binding protein, $\alpha 1$ antitrypsin, $\alpha 1$ antichymotrypsin, $\alpha 2$ macroglobulin, fibrinogen, prothrombin, and complement factors, among others. They are structurally and chemically unrelated, and there is a broad amplitude in their physiological functions, which ranges from inhibition of pathogen growth, facilitation of their removal by phagocytic cells, and elimination of infected cells to other 
unrelated functions, such as providing anti-inflammatory feedback to the immune system or modulation of coagulation (90). CRP is perhaps the most studied of these proteins, and it is frequently used as a diagnostic marker for inflammation. Interestingly, CRP is known to be released locally by cells of the respiratory epithelia and the liver in response to cytokine stimulation and that patients with ARDS have high levels of CRP (91). CRP was identified as a biomarker of disease severity in patients hospitalized with IAV infection at the time of admission (92). However, another study indicates that, although the levels of CRP are elevated in patients with acute lung injury, a higher level of plasma CRP predicts a more favorable outcome in adult patients (93). This protein has both pro-inflammatory and anti-inflammatory functions, and its function remains to be well characterized. Chronic overexpression of these acute phase proteins is also characteristic of some chronic, autoimmune pro-inflammatory diseases, such as RA.

Excessive production of IL6 has been associated with several pathological manifestations, such as Castleman disease or RA. For this reason, IL6 has been extensively investigated as a therapeutic target, leading to the development of monoclonal antibodies, such as tocilizumab, which has already been approved for the treatment of these diseases (94). However, in the case of IAV infection, IL6 seems to have a protective role in the mouse model, promoting viral clearance and limiting inflammation (95), indicating that IL6 blocking agents might not be adequate for inflammation treatment during IAV infection.

\section{IL1 $\beta$}

IL1 $\beta$ belongs to the broad IL1 family. The precursor of IL1 $\beta$ (proIL $\beta$ ) is processed by caspase 1 , which activation is mediated by the action of the inflammasome. IL1 $\beta$ is produced by immune cells, such as monocytes, tissue macrophages, and skin DCs in response to TLR activation, complement components, and other cytokines, such as TNF $\alpha$ (96).

The receptor for IL1 $\beta$, as well as for IL $1 \alpha$, is IL1 receptor type I (IL1RI). The IL1RI presents a toll-IL1-receptor domain (TIR), which is also present in TLRs, and it is necessary for signal transduction. Engagement of IL1 $\beta / \alpha$ to IL1RI leads to the recruitment of the co-receptor chain IL1R accessory protein IL1RAcP. Next, the adaptor protein myeloid differentiation primary response gene 88 (MyD88) interacts with the TIR domain, leading to phosphorylation of the IL1RI-associated kinases, IRAKs. Further phosphorylation steps involving the inhibitor of NF- $\kappa B$ kinase $\alpha$ and $\beta$ $(\mathrm{IKK} \alpha / \beta)$ and the NF-kappa-B essential modulator (NEMO) lead to the subsequent activation of the NF- $\kappa \mathrm{B}$ transcription factors (97). JNK and p38 MAPK pathways are also activated upon IL1RI engagement (98). These events result in the induction of the expression of inflammatory genes including IL $1 \alpha$ and $\beta$, as well as IL6 and RANTES among others, leading to an amplification loop.

While the main function of this cytokine is to mediate inflammation through activation of the NF- $\kappa B$ transcription factors, IL1 $\beta$ signaling has other additional consequences. For instance, the activation of IL1RI include increased expression of cyclooxygenase-2 (COX-2), inducible nitric oxide synthases (iNOS), prostaglandin 2 (PEG2) (71), and adhesion molecules, such as intercellular adhesion molecule-1 (ICAM-1) on mesenchymal cells and vascular-cell adhesion molecule-1
(VCAM-1) on endothelial cells. This latter property promotes the infiltration of inflammatory cells into the extravascular space (99).

IL1 cytokines are highly associated with acute and chronic inflammatory afflictions. As such, therapies to counteract the effect of this cytokine have been developed and are under study. In particular, treatment with an IL1R antagonist (IL1Ra), known under the generic name anakinra, has been approved to relieve symptoms and pain in patients with RA, and it is a standard therapy for autoimmune syndromes in general $(96,100)$.

Several studies suggest that IL1 $\beta$ has important roles in tissue damage in several mouse models of inflammation, including induction of systemic inflammation with turpentine or zymosaninduced peritonitis (101). There is also data indicating an excessive activation of the inflammasome in lung pathology - which is activated by the PB1-F2 protein of influenza virus (102), probably as a consequence of subsequent NF- $\mathrm{KB}$ activation. Interestingly, another study showed a positive effect on survival after administrating the IL1Ra to influenza virus-infected mice (103). However, in another model of influenza virus infection, while IL1 $\beta$-infected mice showed reduced body temperature, mortality was higher in IL1 $\beta$ knock out mice (104). In agreement with this, more recent studies have suggested that the inflammasome, in which IL1 $\beta$ has an important role, is important for mediating healing and reducing lung damage, while it is not necessary for virus clearance or humoral adaptive immune responses (105). Indeed, there is increasing evidence that IL1 $\beta$ has an important role in epithelial repair in patients with ARDS (106-108) and this effect seems to be mediated by epidermal growth factor (EGF)/transforming growth factor- $\alpha$ (TGF- $\alpha$ ) pathway (109). More recently, it has been shown that IL1 $\beta$ activates the expression of the early growth response (Egr) 1 transcription factor through activation of the EGF receptor (EGFR) (110).

Therefore, excessive IL1 $\beta$ responses might contribute to lung injury during severe cases of influenza, but its role in tissue repair seems to be necessary to ensure recovery. Therapeutic strategies targeting this aspect of pathogenesis are complicated given the dual role of IL1 $\beta$ signaling in inflammation and in tissue repair, and a better understanding of the mechanisms of action of IL1 $\beta$ and consequences of altering its functions is needed.

\section{Type I and Type III IFN}

The most important function of type I and type III IFN is to induce the activation of an antiviral state in infected and neighboring cells. For this reason, these cytokines are very important for protecting against acute viral infections. In addition, type I IFNs have also an important role in the stimulation of adaptive immunity $(111,112)$.

The most studied type I IFNs are IFN $\beta$, expressed by virtually all cells, and IFN $\alpha$, produced primarily by hematopoietic cells. Both IFN $\alpha$ and $\beta$ interact with the IFN $\alpha / \beta$ receptor (IFNAR), which results in the activation of the receptor-associated protein tyrosine kinases (JAK1) and tyrosine kinase 2 (TYK2). Then, the transcription factors, STAT1 and STAT2, are phosphorylated, dimerize, and translocate to the nucleus (113), where they assemble with IFN-regulatory factor 9 (IRF9) to form the complex IFN-stimulated gene factor 3 (ISGF3). This complex binds specific sequences in the DNA and promotes transcription of hundreds of ISGs, which leads to numerous changes in the transcriptome of the 
cell thus activating the antiviral response $(114,115)$. Also, under certain conditions, type I IFNs are able to induce the formation and phosphorylation of STAT1 homodimers, which may bind gamma-activated sequences (GAS) and induce the expression of a different set of genes (116). This GAS-stimulated gene response is mainly activated by type II IFN as described below, and is composed principally of pro-inflammatory genes. Interestingly, type I IFN signaling also leads to STAT3 phosphorylation, which downregulates type I IFN-mediated induction of inflammatory mediators (such as MIG and IP10) while supporting ISGF3dependent induction of antiviral genes (117).

Type III IFN or IFN $\lambda$ is a more recently discovered antiviral IFN that triggers STAT1 activation through engagement of an independent heterodimeric receptor, IL-28 receptor $\alpha /$ IL-10 receptor $\beta$ (IL28R $\alpha / \operatorname{IL} 10 R \beta)$ complex $(118,119)$, found primarily on epithelial cells of both the respiratory and gastrointestinal tract. There are three IFN $\lambda$ proteins, IFN $\lambda-1,-2$, and -3 (also known as IL29, IL28A, and IL28B, respectively), all of which signal through the same receptor. Signaling through type III IFN receptor complex results in a cascade of signals similar to that produced by ligation of the type I IFN receptor, which are mediated by JAK1 and TYK2, leading to the formation of a transcription factor complex, ISGF3. Therefore, the biological responses induced by type I and type III IFNs are very similar and mainly characterized by the induction of antiviral responses with the main difference between them being the expression of the receptor in different cell types (120).

While type I IFN is known to be a key mediator of virus clearance during influenza virus infection (121), excessive IFN signaling has detrimental effects on disease severity, mostly as a result of overall increased inflammation (pro-inflammatory cytokines and lung-infiltrating cells), cell death, and oxidative stress that might have damaging effects on the host $(122,123)$. The production of type I IFN and its pathological effects are supported by its role in other immune diseases. In particular, genetic and transcriptomic analysis of blood from systemic lupus erythematosus (SLE) patients, has attributed type I IFN a central role in the pathogenesis of this disease (124). Type I IFN has also been implicated in the pathogenesis of RA (125) and a type IFN I signature has been documented in patients with Aicardi-Goutieres syndrome (126). It has been shown that the type I IFN receptor sensitizes macrophages to death caused by $L$. monocytogenes infection (127). Interestingly, type I IFN also has been associated with endothelial dysfunction through induction of endothelial nitric oxide synthase (128). However, the mechanisms of type I IFN-mediated regulation of oxidative stress have not been analyzed in detail.

While the damaging potential of type I IFN is evident, the main feature of this family of cytokines is that they are crucial inducers of the antiviral response and therefore they are absolutely required to fight IAV infection. Studies performed in mice clearly indicate that viral replication and disease severity are increased in the absence of IFN, indicating that both type I and type III IFN having protective roles (129). Given the importance of type I IFN induction in defeating viral infection at the cellular level, desirable anti-inflammatory therapies to treat IAV or other viral infections should not fully blunt this type of response.

\section{Type II IFN}

Interferon- $\gamma$ is the only member of the type II IFN family and is mainly produced by $\mathrm{T}$ cells and NK cells. The production of IFN $\gamma$ is controlled by IL12 and IL18 released by antigen-presenting cells, such as DCs and macrophages. Type II IFN plays important roles in the stimulation of antigen presentation by macrophages, in activating the cellular Th1 responses upon infection by intracellular pathogens, and in regulating $B$ cell functions (130).

The IFN $\gamma$ receptor (IFNGR) comprises two different subunits, IFNGR1 and IFNGR2. Activation results in signal transduction through JAK1 and JAK2 and subsequent phosphorylation and homo-dimerization of STAT1 transcription factors. STAT1 dimers subsequently translocate to the nucleus and activate the GAS elements (131), which lead to the expression of IFN $\gamma$-related genes. Interestingly, some of these genes are transcription factors (such as IRF1) that can lead to the activation of a second wave of genes (such as IFN $\beta$ ) (130) and thus there is significant overlap between the IFN $\alpha / \beta$ - and IFN $\gamma$-regulated genes.

One of the most important functions of IFN $\gamma$ is that it stimulates antigen presentation by several mechanisms. Thus, IFN $\gamma$ upregulates the expression of the major histocompatibility complex (MHC) class I (132) and MHC class II (133). Interestingly, IFN $\gamma$ also facilitates antigen processing by stimulating the expression of several molecules associated with this function, such as proteasome subunits, including LMP2 and LMP7 (134, 135 ) or of the regulator of the immunoproteosome proteasome activator (PA) 28 (136). At the cellular level, activation of IFN $\gamma$ signaling promotes cell growth and proliferation, but also it has been shown to be important in the upregulation of pro-apoptotic molecules [such as protein kinase R (PKR), the death associated proteins (DAPs), cathepsin D, and surface expression of the $\mathrm{TNF} \alpha$ receptor]. A very important consequence of the activation of macrophages and neutrophils by IFN is the enhancement of microbial killing processes, mainly mediated by induction of the NADPH-dependent phagocyte oxidase system or respiratory burst (release of ROS), stimulation of NO production, and upregulation of lysosomal enzymes $(137,138)$. This defense mechanism, however, is also damaging for infected tissues and has been shown to enhance the pathogenesis during IAV infections $(41,139)$. IFN $\gamma$ has also implicated in the pathology of diseases, such as systemic lupus erythematous (140) or multiple sclerosis (141).

\section{Chemokines}

Chemokines are small chemotactic cytokines that play important roles in driving many components of inflammation, the most important of which is leukocyte migration. Chemokine receptors in the cell surface are transmembrane G protein-coupled receptors (GPCRs), and their activation leads to the transduction of intracellular signaling pathways that promote migration toward the chemokine source. Other functions mediated by chemokines include regulation of cell viability, proliferation, differentiation, and migration (142). The chemokine system is very promiscuous in providing flexibility and specificity in the trafficking of immune cells, and a specific chemokine may act on several leukocyte populations to coordinate the recruitment of cells with related functions. 


\section{RANTES}

RANTES also known as chemokine (C-C motif) ligand 5 (CCL5), plays an active role in recruiting leukocytes to inflammatory sites. In particular, it has been shown to induce the migration and recruitment of T cells, DCs, macrophages, monocytes, eosinophils, NK cells, mast cells, and basophils (143-146). Also, it induces the proliferation and activation of certain NK cells. RANTES is produced by macrophages, DCs, T lymphocytes, platelets, eosinophils, fibroblasts, endothelial, and epithelial cells. In general, production of RANTES is associated with viral infections. Interestingly, RANTES is a co-receptor for HIV (147) and for this reason, there is a field of intensive research to develop pharmacological inhibitors of this receptor with the ultimate goal of producing a therapeutic agent $(148,149)$. High levels of RANTES have also been associated with extensive inflammation of the lung in cases of avian influenza (150) and other viral infections. Deficiency of the receptor for this chemokine, CCR5, which is also the receptor for MIP $1 \alpha$ and MIP $1 \beta$, resulted in increased mortality in IAV-infected mice, suggesting that the function of those chemokines is important for virus clearance, and therefore, they are not promising targets to reduce inflammation (151).

\section{IP10}

IP10 or (C-X-C motif) ligand (CXCL) 10 is a protein highly associated with the presence of viral infection. Several cell types release IP10, including T lymphocytes, neutrophils, monocytes, DCs, endothelial and epithelial cells, and fibroblasts. IP10 expression is induced by IFN $-\gamma$ and the gene features ISRE and NF- $\kappa$ B binding sites in the promoter (152), allowing for direct upregulation upon virus infection (153). IP10 interacts with the $\mathrm{C}-\mathrm{X}-\mathrm{C}$ receptor (CXCR) 3 to activate the main target cells, which include $\mathrm{T}$ and B lymphocytes, NK cells, DCs, and macrophages. As a consequence of this interaction, signal transduction leads to chemotaxis toward inflamed or infected areas, apoptosis, and proliferation or cell growth inhibition (154). IP10 is known to contribute to the pathogenesis of several infectious diseases (154) and of many autoimmune diseases, such as type 1 diabetes, RA, psoriatic arthritis, or SLE (155). Experiments in mice have shown that the lack of IP10 or its receptor reduces the severity of ARDS during influenza virus infection, suggesting the potential of this signaling pathway as a therapeutic target for ARDS treatment (156).

\section{IL8}

IL8 or CXCL8 is a potent neutrophil attractant and activator, but also acts on monocytes and mast cells, which express the IL8 receptors, CXCR1 and CXCR2. This chemokine is mainly produced by macrophages, epithelial cells, and endothelial cells (157). Interestingly, monocytes and macrophages produce low amounts of IL8 during influenza virus infection (158), while epithelial cells produce high levels of IL8 in vitro (159). Several transcription factors activated upon viral recognition have been shown to bind IL8 promoter and stimulate IL8 production. These include NF$\kappa \mathrm{B}$, the activator protein 1 (AP-1), the CCAAT-enhancer-binding protein (C/EBP)- $\beta$, IRF1, and IRF3 $(160,161)$. IL8 has a significant role in ARDS, which is characterized by a large influx of neutrophils to the lung during severe influenza (162). Neutrophils protect against microbial infection through the release numerous factors such as ROS, proteinases, and neutrophil extracellular traps, molecules that, when produced in excess, might also have damaging effects (163). In addition to the contribution of IL8 to pathogenesis through increased inflammation via neutrophil recruitment, patients with ARDS also have been shown to present auto-IL8 antibodies that complex with IL8. These complexes are also able to induce chemoattraction of neutrophils, but interestingly, they trigger superoxide and myeloperoxidase release (neutrophil respiratory burst and degranulation) from human neutrophils in a Fc $\gamma$ RIIa-dependent way (164).

\section{MCP1}

MCP1 or CCL2 regulates the migration and infiltration of cells expressing the receptor CCR2, which includes monocytes, memory T lymphocytes, and NK cells, and is produced either constitutively or after induction by oxidative stress or pro-inflammatory mediators. It also participates in the phenotypic polarization of memory T cells toward a Th2 phenotype $(165,166)$. MCP1 is produced by several different cell types, including endothelial, fibroblast, epithelial, smooth muscle, and monocyte cells among others, monocyte and macrophages being the main sources (167). This chemokine has been implicated in the pathogenesis of several diseases, such as asthma (168), RA, cardiovascular diseases, cancer (169), and some neuropathologies (170). CCR2 signaling results in the activation of PI3K, MAPK, and protein kinase C, and therefore, elicits a broad range of cellular responses $(171,172)$. In the context of IAV infection, conflicting results have been reported regarding MCP1 function. On the one hand, one study showed that neutralization of MCP1 in vivo reduced the immunopathology in a mouse model (173). However, a different report showed increased alveolar epithelial damage and apoptosis upon a similar treatment (174). A separate report showed that CCR2 ${ }^{-1-}$ mice infected with IAV presented decreased pathological signs, but higher pulmonary titers early after infection (151). Thus, further characterization on the role of this chemokine is necessary to determine its potential as a target for anti-inflammatory therapy.

\section{MIP1 $\beta$}

Macrophage inflammatory protein-1 $\beta$ or CCL4 is also involved in the recruitment of multiple immune cells, such as monocytes, T-lymphocytes, monocytes, eosinophils, basophils, DCs, and NK cells (175). It also induces activation of these cells and increased adhesion (176). Low levels are constitutively expressed but its production is activated by multiple inducers (such as PAMPs and cytokines) in different cell types, including monocytes, macrophages, neutrophils, DCs, epithelial cells, fibroblast, and multiple cells from the nervous system (175). The receptor for MIP $1 \beta$ is CCR5, although it is known that a natural truncated form of MIP1 $\beta$, which lacks two N-terminal amino acids, also binds and signals through CCR1 and CCR2B (177). Associations with autoimmune diseases, such as SLE, have been also reported for MIP1 $\beta$ (178).

\section{Modulating the Innate Immune Response During Severe IAV Infection}

As described above, the current literature indicates a clear role for hypercytokinemia during severe IAV infection. Initially, cytokine 
production is induced following detection of the virus by cellular PRRs (Figure 1). Therefore, the primary treatment of IAV infection should be antiviral compounds, such as neuraminidase inhibitors, which will limit viral replication and spread, and therefore minimize the production of pro-inflammatory cytokines. Inflammation results in the induction of multiple cellular processes that lead to increased oxidative stress, apoptosis, necrosis, altered adhesion, and migration of immune cells to the lung. In addition, these processes lead to the release of additional secondary mediators and induction of cytokines, which results in amplified inflammation leading to increased damage (Figure 1). Therefore, it is worth considering therapies that modulate these detrimental processes in combination with antiviral agents. Targeting some of the most prevalent cytokines or related signaling pathways in severe influenza in mouse models, using either knock out animals or blocking agents, have been shown to reduce lung damage and mortality in multiple studies as indicated in the previous section, supporting the idea that anti-inflammatory agents inhibiting the same pathways could be beneficial in humans. One of the most important parameters that should be evaluated among these anti-inflammatory agents is that the treatment should reduce the negative effects of inflammation but not the innate and adaptive immune arms that are responsible for restricting viral replication and spread. However, the pathways initiated by the most prevalent cytokines are very redundant and dissecting these complex responses is very challenging. Specifically, blockade of TNF $\alpha$ and IL1 $\beta$ have shown a potential benefit in the mouse model, while blocking other cytokines, such as type I or III IFN or IL6-worsened disease outcome. Inhibition of specific chemokines or their receptors are also possible strategies. A few reports have been reported evaluating the consequence of blocking their function, which indicated that IP10 and MCP1 might have beneficial effects on reducing morbidity due to inflammation, while deficiency in RANTES expression seems to be detrimental. Further studies in animal models should be performed to better understand which of these pathways could be targeted as an antiinflammatory therapy during severe influenza disease. In addition to cytokines and chemokines, other elements of the inflammatory response are under consideration for this purpose. In this section, we review those therapies that have been evaluated in the clinic or that have shown promising results in preclinical studies, such as broad-spectrum therapies, other signaling mediators or their receptors, or molecules involved in the generation of oxidative stress.

\section{Corticosteroids}

Corticosteroid treatment has been proven to be safe in patients with ARDS and is associated with reduced inflammation and improved clinical status (179). For this reason, the use of these drugs has been considered for the treatment of severe influenza

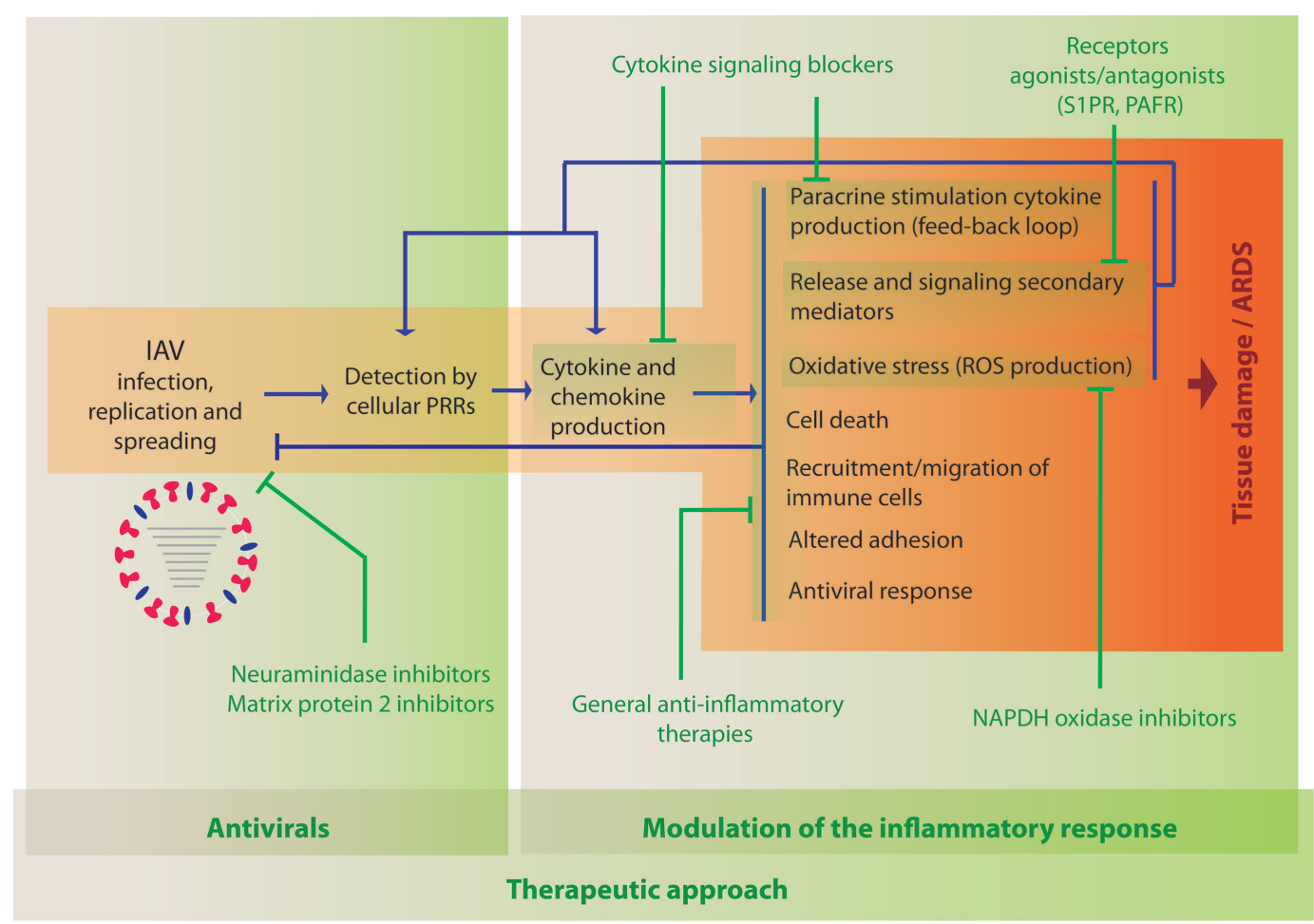

FIGURE 1 | Activation of innate immune processes by IAV and therapeutic opportunities to modulate the immune response. When IAV invades a new host, it infects and replicates in cells of the respiratory tract. Cellular sensors, such as TLRs, RLRs, NLRs, and CLRs, recognize the virus PAMPs and initiate immune responses leading to the activation of defense mechanisms to counteract viral infection. The development of the inflammatory response is accompanied by multiple changes in gene expression that also result in damage of the infected tissue. Antiviral treatment is the first opportunity to reduce viral load and inflammation (indicated in green, left panel). The use of anti-inflammatory drugs to reduce cytokine- and chemokine-induced damage that could be used in combination with antiviral therapies is under investigation (indicated in green, right panel). 
and has, in fact, been used in several cases of avian influenza (H5N1) virus infection (180). In addition, corticosteroids are regularly used in long-term treatment for asthma and chronic obstructive pulmonary disease (COPD). Thus, understanding the effect of these drugs during influenza virus infection is very relevant not only for their anti-inflammatory use in cases of IAV infection but also to determine the best methods to manage these high risk patients in the clinical setting.

Several studies have evaluated the consequences of using corticosteroids in humans with influenza infection, with varying results. A study by Quispe-Laime reported a reduction in lung injury and multiple organ dysfunctions in $\mathrm{H} 1 \mathrm{~N} 1$ influenza virusinfected patients treated with corticosteroids (181). However, as recently reviewed by Hui and Lee, several clinical trials indicate that the administration of these steroids during influenza virus infection, either in the presence or absence of neuraminidase inhibitors, has either no effect or even a detrimental effect (182). A retrospective study by Kudo and colleagues evaluated the effect of corticosteroid administration in patients with 2009 H1N1 IAV infection with pneumonia and did not find a negative effect of the steroid treatment (183). On the other hand, Lee et al., in a prospective study with adult patients infected with $\mathrm{H} 3 \mathrm{~N} 2$ IAV, showed that the administration of systemic corticosteroid to reduce exacerbation of asthma or in patients with COPD correlated with delayed viral clearance (184). Accordingly, another retrospective study in adults infected with $2009 \mathrm{H} 1 \mathrm{~N} 1$ influenza virus showed an association of corticosteroid treatment with increased mortality (185). An interesting study by Thomas et al. showed that glucocorticosteroid treatment prior to IAV infection inhibits antiviral responses and the release of cytokines when tested in cultured primary human airway cells, which resulted in increased viral replication (186). Similarly, an in vivo experiment in the same study showed higher replication in a mouse model after treatment, which resulted in enhanced inflammation. This is in agreement with the recent meta-analysis of the literature performed by Zhang et al., where they concluded that corticosteroids are likely to increase mortality and morbidity by influenza 2009 $\mathrm{H} 1 \mathrm{~N} 1$ virus (187).

Consequently, the current literature suggests that the corticosteroid treatment is not a good choice for the treatment of acute inflammation during influenza virus infection, probably due to increased viral replication as a consequence of reduced antiviral responses (188). Accordingly, WHO discourage the use of corticosteroid drugs as routine treatment for severe influenza due to the paucity of evidence for beneficial effects (189). Further research in this field should be done, given the routine use of chronic corticosteroids treatment in some other medical conditions, such as asthma and COPD, both of which are considered high risk populations for influenza disease.

\section{Statins}

Statins are also a class of drugs with extensive use in the clinic given their ability to decrease cholesterol levels, thus reducing the risk of cardiovascular disease. These drugs are inhibitors of the hydroxyl methylglutaryl-coenzyme A (HMG-CoA) reductase enzyme, acting in the cholesterol synthesis pathway. Interestingly, these drugs also have anti-inflammatory properties (190), which have been analyzed in the context of influenza infection (191). By altering the cholesterol synthesis route, statins also reduce the synthesis of lipid intermediates necessary for isoprenylation of multiple proteins. Consequently, multiple intracellular signaling pathways activated during the development of the inflammatory response are also affected (192).

An observational study that included more than 3000 patients hospitalized with influenza in the United States identified an association of statin use with reduced mortality (193). Other clinical studies have also shown that statin use could be beneficial in the treatment of influenza $(194,195)$, while yet other studies did not find supporting evidence for the use of this type of drug (196, 197). These retrospective studies, however, have the limitation that patients who are prescribed statins are some of those who are already at a higher risk for developing severe disease (due to preexisting cardiovascular disease) and timing, duration and dose of the statin treatments are difficult to control. An interesting review by Mehrbod et al. (198) provides more detailed information on clinical trials evaluating the use of statins in IAV infections.

While the literature on this topic shows varied results, there is increasing evidence for a possible beneficial effect of the use of statins during influenza treatment, and further experimentation to confirm a positive effect should be developed. This is supported by several in vitro and in vivo studies that have indicated that, in addition to diminishing the production of cytokines upon influenza virus infection, statins also seem to result in decreased levels of viral replication (198-200).

\section{$\mathrm{N}$-acetylcysteine}

$\mathrm{N}$-acetylcysteine is also a commonly used compound, which is mainly known for its mucolytic as well as anti-oxidant properties. Interestingly, anti-inflammatory properties have been also attributed to this molecule, which are probably associated with its anti-oxidant function by diminishing oxidative stress during inflammation. Related to this, animal models of systemic endotoxin-induced shock or acute lung injury showed reduced production of cytokines and tissue damage upon treatment with $\mathrm{N}$-acetylcysteine (201-203).

Although the effect of this molecule in the context of influenza treatment has not been broadly studied, there are some reports indicating a possible beneficial effect. One study by Geiler et al. showed reduction of viral replication and pro-inflammatory cytokines in human lung epithelial cell lines upon infection with H5N1 influenza virus (204). The mechanism of inhibition seemed to be related to reduced NF- $\kappa B$ and MAPK p38 activation. These data were confirmed by a similar study where an H3N2 IAV and an influenza B virus strain were evaluated (205). Data from in vivo studies also seem to indicate that $N$-acetylcysteine might help to protect against IAV-induced pathology (206). It is important to note that in this case, contradictory reports have also been published, such as the study by Garigliany and Desmecht, which did not find an effect of the treatment in the mouse model (207). In humans, de Flora et al. (208) showed a long-term positive effect of $\mathrm{N}$-acetylcysteine administration on the development of influenza or influenza-like symptoms. Therefore, although the amount of data reported is scarce, there seems to be evidence for a possible safe and beneficial effect for the use of $\mathrm{N}$-acetylcysteine to treat 
inflammation by influenza without enhancing viral replication. However, studies evaluating this molecule in humans are very limited, and more extensive work is needed to obtain conclusive information.

\section{Macrolides}

Macrolides, which are generally used for their antibacterial activity, also have immunomodulatory properties. They have been shown to reduce the expression of several cytokines and chemokines, such as IL6, IL8, and TNF $\alpha$ during different inflammatory processes. The ability of macrolides to interfere with multiple signaling pathways accounts for these immunomodulatory properties. For instance, some macrolides suppress NF- $\mathrm{KB}$ and AP-1 signaling $(209,210)$, affect intracellular $\mathrm{Ca}^{2+}$ dynamics (211), and inhibit the ERK1/2 pathway (212).

In vitro studies have shown that clarithromycin clearly reduces viral replication in epithelial cell lines approximately $4-7 \mathrm{~h}$ after viral adsorption (213). This effect is therefore also independent of the anti-inflammatory activity and might be mediated by alteration in cell signaling pathways. In vivo studies also support a potential role for the macrolides in improving recovery upon infection with IAV (214).

In the clinic, macrolides are sometimes administered in cases of influenza to treat secondary bacterial infections and because of their anti-inflammatory effects, clarithromycin being the most frequently prescribed first-line drug (215). Higashi et al. (216) analyzed the benefits of clarithromycin treatment in combination with neuraminidase inhibitors in patients with influenza infection. Their data indicated a possible effect in reducing fever, but they did not observe any differences in IL6 serum levels. However, another study could not find any association between significant improvement of symptoms and the use of macrolides.

In general, the number of studies evaluating macrolides in IAV infection is very limited. While in vitro and in vivo data showed promising results as indicated by a reduction of pro-inflammatory molecules alongside reduced viral replication, the small number of clinical studies does not suggest a significant benefit. Also, the use of antibiotics should be limited to cases with secondary bacterial infections, given the risk for emerging resistances. In addition, mice studies have shown that treatment with a combination of several antibiotics leads to impaired innate and adaptive immune responses and delayed virus clearance as a consequence of changes in the respiratory microbiota $(217,218)$ and therefore its use during influenza virus infection in humans should be further analyzed and cautiously used during severe infections.

\section{COX-2 Inhibitors}

Cyclooxygenase enzymes catalyze the conversion of arachidonic acid to prostaglandins, which play important roles in modulating immune responses and inflammation. While the isoform COX-1 is constitutively expressed, COX-2 is induced by several stimuli, such as LPS, pro-inflammatory cytokines, and growth factors (219). Importantly, COX enzymes are main targets for nonsteroidal anti-inflammatory drugs including aspirin, ibuprofen, diclofenac, naproxen, and for selective COX-2 inhibitors, such as celecoxib and nimesulide, and are therefore very available and frequently used as treatment for other conditions.
Considering the well-described pro-inflammatory role of COX-2, studies to understand its function in influenza pathogenesis have been performed. COX-2 knock out mice infected with IAV showed reduced levels of pro-inflammatory cytokines and mortality, but also increased levels of replication (220). Interestingly, COX-1 ablation showed opposite results, with augmented and earlier inflammatory responses. COX-2 expression was observed to be elevated in autopsy tissue samples from patients infected by H5N1 IAV $(182,221)$. In vitro experiments have shown that COX-2 inhibitors play a regulatory role in mediating pro-inflammatory responses after H5N1 infection (221, 222) and have been shown to have a direct antiviral effect in human macrophages infected with H5N1 influenza virus (223). However, another in vivo study did not find a beneficial effect from celecoxib treatment in mice infected with an $\mathrm{H} 3 \mathrm{~N} 2$ virus. Therefore, data regarding COX-2 inhibitors are also controversial. Another in vivo study did observe a positive effect of celecoxib administration when used in combination with mesalazine or 5aminosalicylic acid (another anti-inflammatory drug) in addition to a neuraminidase inhibitor in mice challenged with H5N1 IAV (224), supporting the idea that a combination treatment might be more efficient.

To date, there are no systematic human studies evaluating COX2 inhibitors for influenza treatment. The event that these studies move forward is important to consider the selectivity for COX-2 inhibitors, since COX-1 inhibitors would have an opposite effect, increasing inflammation, and pathogenesis. Indeed, an increased risk of mortality during influenza virus infection was associated with aspirin, paracetamol, and diclofenac in animal models in a meta-analysis of the literature (225).

\section{Peroxisome Proliferator-Activated Receptor Agonists}

Peroxisome proliferator-activated receptors (PPAR) are nuclear receptors and ligand-activated transcription factors that control a number of target genes upon assembly of a transcriptional complex. There are several PPAR, but in general, they are regulators of energy balance, including glucose homeostasis, fatty acid oxidation, and lipid metabolism, and are frequently used in the treatment of diabetes (226).

Several in vivo studies point to a possible benefit of the use of these drugs in treating influenza infection. Moseley at al. showed a reduction in morbidity and mortality in mice infected with two different H1N1 strains and treated with PPAR agonists (227). Similarly, PPAR agonist treatment of mice challenged with an $\mathrm{H} 5 \mathrm{~N} 1$ or an $\mathrm{H} 2 \mathrm{~N} 2$ IAV led to decreased inflammation and morbidity, and increased survival (228-230), using a cyclopentenone prostaglandin (prostanoid 15-deoxy- $\Delta 12,14$ prostaglandin-j2), observed a reduction in the levels of cytokines and chemokines in a mouse model of influenza in addition to a reduction in viral titers, and this effect was shown to be mediated by PPAR $\gamma(230)$.

While these drugs have not been thoroughly studied for influenza treatment and no human studies have been performed so far, exploring their potential would be of great interest given their current use in the clinic and availability, which would facilitate their study in clinical trials (231). 


\section{Sphingosine-1-Phosphate-1 Receptor Agonists}

Sphingosine-1-phosphate (S1P) is a lipid signaling mediator synthesized from ceramides. The laboratory of Dr. Oldstone at The Scripps Research Institute (La Jolla, CA, USA) has focused on the use of S1PR agonists as a possible therapeutic to alleviate the inflammatory response arising during IAV infection, providing very interesting insights about the mechanisms of immunopathogenesis. They were first able to demonstrate that the administration of a promiscuous $\mathrm{S} 1 \mathrm{P}$ receptor agonist led to a significant reduction of cytokines and chemokines upon influenza infection in the mouse model (232-234). This reduction of the inflammatory response correlated with a decrease in lung injury and improved survival upon infection (235). Importantly, the reduction of inflammation was not accompanied by a delayed clearance of the virus, indicating a potential for the use of these drugs as a therapeutic agent (234). Further work using S1PR agonists led them to describe a central role for endothelial cells in the generation of the cytokine storm (236). They further searched for the signaling pathways that the S1PR agonists might use to exert these anti-inflammatory-protective functions during IAV infection and found that the effect observed is independent of TLR3, TLR7, or cytosolic signaling pathways (237). In addition, they found an essential role for IL1R and MyD88/TRIF signaling in cytokine amplification (237). Therefore, although S1PR agonists are under investigation in mice and ferrets for influenza treatment (238), results from these studies are promising as a possible future treatment for hypercytokinemia in severe cases of influenza. One S1PR agonist has been approved in the clinic by the FDA for the treatment of relapsing-remitting multiple sclerosis. However, adverse effects have been noted in the use of this drug, and the safety profile of this and other S1PR agonists should be further investigated (239).

\section{Platelet-Activating Factor Receptor Antagonists}

Platelet-Activating Factor (PAF) is a phospholipid mediator involved in many cellular processes including cell motility and synthesis of cytokines and other signaling mediators (240). PAF signaling occurs through the PAF receptor (PAFR), which is a single GPCR, expressed in the plasma and nuclear membranes of leukocytes, endothelial cells, epithelial cells, smooth muscle cells, and platelets (240). It is known that expression of PAFR in the airway is upregulated by IAV infection, and it is believed that this facilitates bacterial adherence and therefore susceptibility to Streptococcus pneumonia (241).

The use of PAFR antagonists has been proposed in different pathological settings, including influenza, mainly due to their anti-inflammatory properties (242). Using PAFR knock out mice and antagonists, Garcia et al. demonstrated that eliminating or counteracting these receptors reduced lung injury, infiltration of mononuclear cells and neutrophils, and the expression of IL12, RANTES, and IFN $\gamma$ while not affecting the levels of IL6 and increasing IL1 $\beta$ production (243). This overall reduced immune response did not result in an elevated level of viral replication. A mechanistic analysis showed activation of TLR7/8 during infection was dependent on PAFR. While according to these data, PAFR antagonists could be candidates to treat inflammation during influenza, further characterization of the effect of these drugs should be performed.

\section{Other Candidates}

Other anti-inflammatory therapies have been tested in animal models resulting in reduced inflammation, morbidity, and mortality. While these studies support the potential positive effect of immunomodulatory therapy in severe influenza, the scientific data in this field are very preliminary, and extensive investigation is needed to develop these treatments for human use. Here we discuss some of these treatments.

NADPH oxidases, enzymes that are involved in ROS production, have also been proposed as targets for reducing IAVinduced inflammation. There is evidence that activation of NOX2 promotes lung oxidative stress, inflammation, injury, and dysfunction resulting from infection with IAV ranging from low to high pathogenicities (244). Apocynin, a NOX2 inhibitor, inhibited influenza-induced hypercytokinemia and ROS production in airway epithelial and immune cells in vitro, while not affecting viral replication (41).

A study by Sharma et al. analyzed the effect of other two orally available and approved anti-inflammatory drugs, a phosphodisesterase- 4 inhibitor and a selective serotonin reuptake inhibitor. This study showed a clear reduction in the levels of cytokines and chemokines, lung infiltration, alveolitis, and overall lower mortality in H1N1-infected mice, all while not affecting the levels of viral replication (245).

Another research group further explored the combination of antiviral and anti-inflammatory therapy and generated a novel compound with these two properties by conjugating two drugs, zanamivir (a neuraminidase inhibitor) and caffeic acid (cytokine suppressor) (246). This innovative method provided improved protection in mice against $\mathrm{H} 1 \mathrm{~N} 1$ and $\mathrm{H} 5 \mathrm{~N} 1 \mathrm{IAV}$.

\section{Concluding Remarks}

There is substantial information in the literature supporting the association of influenza pathogenesis with high levels of inflammation and production of cytokines and chemokines, highlighting the opportunity to identify immunomodulatory drugs that could reduce the inflammation-associated damage in the lung seen in severe cases of influenza. These therapies should be evaluated in combination with antivirals, which control virus replication and spread. Reduction of viral load with antiviral drugs also acts to decrease inflammation by lowering the presence of PAMPs to be sensed by cellular PRRs. In addition, one crucial aspect to assess when testing these drugs is to assure that the treatment does not provide an environment for enhanced replication due to a general shutdown of the innate and adaptive immunity.

To date, the therapies studied in humans have commonly used broad-spectrum anti-inflammatory drugs, which are frequently used for other affections. Corticosteroids are a good example of those therapies, which are frequently used in patients with asthma and COPD, and have been evaluated in multiple studies with conflicting results. Some of those studies point to a possible detrimental role of treatment with corticosteroids, and their use 
should be avoided if possible until their effect is better understood. Other broad-spectrum anti-inflammatory drugs that could be beneficial are statins, $\mathrm{N}$-acetylcysteine, and COX-2 inhibitors. However, there is no sufficient data in the current literature to justify their use. More specific treatments that have been explored in animal models include blocking cytokines, such as TNF $\alpha$ or IL1 $\beta$, reducing the oxidative stress through NADPH inhibitors, or the use of inhibitors for receptors for secondary inflammatory mediators, such as PAFR or S1PR. As for the last examples, targeting cell surface receptors in immune cells is an attractive approach since this would facilitate cellular accessibility of the drug. Further

\section{References}

1. CDC. People at High Risk of Developing Flu-Related Complications (2015). Available from: http://www.cdc.gov/flu/about/disease/high_risk.htm

2. CDC. 2014-2015 Influenza season week 10 ending March 14, 2015. Fluview. Influenza Hospitalization Surveillance Network (FluSurv-NET) (2015). Available from: http://www.cdc.gov/flu/weekly/pdf/External_F1516.pdf

3. CDC. Estimates of deaths associated with seasonal influenza - United States, 1976-2007. MMWR Morb Mortal Wkly Rep (2010) 59:1057-62.

4. Medina RA, Garcia-Sastre A. Influenza A viruses: new research developments. Nat Rev Microbiol (2011) 9:590-603. doi:10.1038/nrmicro2613

5. CDC. Interim Risk Assessment and Biosafety Level Recommendations for Working With Influenza A(H7N9) Viruses (2013). Available from: http://www. cdc.gov/flu/avianflu/h7n9/risk-assessment.htm

6. Van Kerkhove MD. Brief literature review for the WHO global influenza research agenda - highly pathogenic avian influenza H5N1 risk in humans. Influenza Other Respir Viruses (2013) 7(Suppl 2):26-33. doi:10.1111/irv.12077

7. Eccles R. Understanding the symptoms of the common cold and influenza. Lancet Infect Dis (2005) 5:718-25. doi:10.1016/S1473-3099(05)70270-X

8. Kuiken T, Taubenberger JK. Pathology of human influenza revisited. Vaccine (2008) 26(Suppl 4):D59-66. doi:10.1016/j.vaccine.2008.07.025

9. Short KR, Kroeze EJ, Fouchier RA, Kuiken T. Pathogenesis of influenzainduced acute respiratory distress syndrome. Lancet Infect Dis (2014) 14:57-69. doi:10.1016/S1473-3099(13)70286-X

10. Bruder D, Srikiatkhachorn A, Enelow RI. Cellular immunity and lung injury in respiratory virus infection. Viral Immunol (2006) 19:147-55. doi:10.1089/ vim.2006.19.147

11. Imai Y, Kuba K, Neely GG, Yaghubian-Malhami R, Perkmann T, Van Loo G, et al. Identification of oxidative stress and toll-like receptor 4 signaling as a key pathway of acute lung injury. Cell (2008) 133:235-49. doi:10.1016/j.cell.2008. 02.043

12. Uiprasertkul M, Kitphati R, Puthavathana P, Kriwong R, Kongchanagul A, Ungchusak K, et al. Apoptosis and pathogenesis of avian influenza A (H5N1) virus in humans. Emerg Infect Dis (2007) 13:708-12. doi:10.3201/eid1305. 060572

13. McCullers JA. Insights into the interaction between influenza virus and pneumococcus. Clin Microbiol Rev (2006) 19:571-82. doi:10.1128/CMR. 00058-05

14. Jamieson AM, Pasman L, Yu S, Gamradt P, Homer RJ, Decker T, et al. Role of tissue protection in lethal respiratory viral-bacterial coinfection. Science (2013) 340:1230-4. doi:10.1126/science. 1233632

15. McCullers JA. The co-pathogenesis of influenza viruses with bacteria in the lung. Nat Rev Microbiol (2014) 12:252-62. doi:10.1038/nrmicro3231

16. Goulding J, Godlee A, Vekaria S, Hilty M, Snelgrove R, Hussell T. Lowering the threshold of lung innate immune cell activation alters susceptibility to secondary bacterial superinfection. J Infect Dis (2011) 204:1086-94. doi:10. 1093/infdis/jir467

17. Cohen M, Zhang XQ, Senaati HP, Chen HW, Varki NM, Schooley RT, et al. Influenza A penetrates host mucus by cleaving sialic acids with neuraminidase. Virol J (2013) 10:321. doi:10.1186/1743-422X-10-321

18. Paludan SR, Bowie AG. Immune sensing of DNA. Immunity (2013) 38:870-80. doi:10.1016/j.immuni.2013.05.004

19. Takeuchi O, Akira S. Pattern recognition receptors and inflammation. Cell (2010) 140:805-20. doi:10.1016/j.cell.2010.01.022 research to bring these therapies closer to the clinic in the context of IAV infection is needed, as well as for the identification of novel immunomodulatory agents.

\section{Acknowledgments}

We thank Anthony C. Fredericks for kindly reviewing the manuscript. We also acknowledge funding by the National Institutes of Health (HHSN272201400008C contract and 5R01AI073450-07) to AF-S, as well as the reviewers of this manuscript for useful suggestions.

20. Lupfer C, Kanneganti TD. The expanding role of NLRs in antiviral immunity. Immunol Rev (2013) 255:13-24. doi:10.1111/imr.12089

21. Pothlichet J, Meunier I, Davis BK, Ting JP, Skamene E, Von Messling V, et al. Type I IFN triggers RIG-I/TLR3/NLRP3-dependent inflammasome activation in influenza A virus infected cells. PLoS Pathog (2013) 9:e1003256. doi:10. 1371/journal.ppat.1003256

22. Allen IC, Scull MA, Moore CB, Holl EK, Mcelvania-Tekippe E, Taxman DJ, et al. The NLRP3 inflammasome mediates in vivo innate immunity to influenza A virus through recognition of viral RNA. Immunity (2009) 30:556-65. doi:10.1016/j.immuni.2009.02.005

23. Ichinohe T, Pang IK, Iwasaki A. Influenza virus activates inflammasomes via its intracellular M2 ion channel. Nat Immunol (2010) 11:404-10. doi:10.1038/ ni.1861

24. Segovia J, Sabbah A, Mgbemena V, Tsai SY, Chang TH, Berton MT, et al TLR2/MyD88/NF-kappaB pathway, reactive oxygen species, potassium efflux activates NLRP3/ASC inflammasome during respiratory syncytial virus infection. PLoS One (2012) 7:e29695. doi:10.1371/journal.pone.0029695

25. Kawai T, Akira S. The role of pattern-recognition receptors in innate immunity: update on toll-like receptors. Nat Immunol (2010) 11:373-84. doi:10. 1038/ni. 1863

26. Kulkarni R, Behboudi S, Sharif S. Insights into the role of toll-like receptors in modulation of T cell responses. Cell Tissue Res (2011) 343:141-52. doi:10. 1007/s00441-010-1017-1

27. Blasius AL, Beutler B. Intracellular toll-like receptors. Immunity (2010) 32:305-15. doi:10.1016/j.immuni.2010.03.012

28. Kingeter LM, Lin X. C-type lectin receptor-induced NF-kappaB activation in innate immune and inflammatory responses. Cell Mol Immunol (2012) 9:105-12. doi:10.1038/cmi.2011.58

29. Wang SF, Huang JC, Lee YM, Liu SJ, Chan YJ, Chau YP, et al. DC-SIGN mediates avian $\mathrm{H} 5 \mathrm{~N} 1$ influenza virus infection in cis and in trans. Biochem Biophys Res Commun (2008) 373:561-6. doi:10.1016/j.bbrc.2008.06.078

30. Londrigan SL, Turville SG, Tate MD, Deng YM, Brooks AG, Reading PC. Nlinked glycosylation facilitates sialic acid-independent attachment and entry of influenza A viruses into cells expressing DC-SIGN or L-SIGN. J Virol (2011) 85:2990-3000. doi:10.1128/JVI.01705-10

31. Ramos I, Fernandez-Sesma A. Cell receptors for influenza a viruses and the innate immune response. Front Microbiol (2012) 3:117. doi:10.3389/fmicb. 2012.00117

32. Iwasaki A, Pillai PS. Innate immunity to influenza virus infection. Nat Rev Immunol (2014) 14:315-28. doi:10.1038/nri3665

33. Braciale TJ, Sun J, Kim TS. Regulating the adaptive immune response to respiratory virus infection. Nat Rev Immunol (2012) 12:295-305. doi:10.1038/ nri3166

34. Gonzalez SF, Lukacs-Kornek V, Kuligowski MP, Pitcher LA, Degn SE, Turley SJ, et al. Complement-dependent transport of antigen into B cell follicles. J Immunol (2010) 185:2659-64. doi:10.4049/jimmunol.1000522

35. Chiu C, Openshaw PJ. Antiviral B cell and T cell immunity in the lungs. Nat Immunol (2015) 16:18-26. doi:10.1038/ni.3056

36. Piwpankaew Y, Monteerarat Y, Suptawiwat O, Puthavathana P, Uipresertkul M, Auewarakul P. Distribution of viral RNA, sialic acid receptor, and pathology in H5N1 avian influenza patients. APMIS (2010) 118:895-902. doi:10. 1111/j.1600-0463.2010.02676.x

37. Shieh WJ, Blau DM, Denison AM, Deleon-Carnes M, Adem P, Bhatnagar J, et al. 2009 pandemic influenza A (H1N1): pathology and pathogenesis of 100 
fatal cases in the United States. Am J Pathol (2010) 177:166-75. doi:10.2353/ ajpath.2010.100115

38. Weinheimer VK, Becher A, Tonnies M, Holland G, Knepper J, Bauer TT, et al. Influenza A viruses target type II pneumocytes in the human lung.J Infect Dis (2012) 206:1685-94. doi:10.1093/infdis/jis455

39. Ramos I, Fernandez-Sesma A. Innate immunity to $\mathrm{H} 5 \mathrm{~N} 1$ influenza viruses in humans. Viruses (2012) 4:3363-88. doi:10.3390/v4123363

40. Harijith A, Ebenezer DL, Natarajan V. Reactive oxygen species at the crossroads of inflammasome and inflammation. Front Physiol (2014) 5:352. doi:10. 3389/fphys.2014.00352

41. Ye S, Lowther S, Stambas J. Inhibition of reactive oxygen species production ameliorates inflammation induced by influenza A viruses via upregulation of SOCS1 and SOCS3. J Virol (2015) 89:2672-83. doi:10.1128/JVI.03529-14

42. Shen HM, Pervaiz S. TNF receptor superfamily-induced cell death: redoxdependent execution. FASEB J (2006) 20:1589-98. doi:10.1096/fj.05-5603rev

43. Hsu H, Huang J, Shu HB, Baichwal V, Goeddel DV. TNF-dependent recruitment of the protein kinase RIP to the TNF receptor-1 signaling complex. Immunity (1996) 4:387-96. doi:10.1016/S1074-7613(00)80252-6

44. Vanlangenakker N, Vanden Berghe T, Vandenabeele P. Many stimuli pull the necrotic trigger, an overview. Cell Death Differ (2012) 19:75-86. doi:10.1038/ cdd.2011.164

45. Peiris JS, Cheung CY, Leung CY, Nicholls JM. Innate immune responses to influenza A H5N1: friend or foe? Trends Immunol (2009) 30:574-84. doi:10. 1016/j.it.2009.09.004

46. Shen Y, Lu H, Qi T, Gu Y, Xiang M, Lu S, et al. Fatal cases of human infection with avian influenza A (H7N9) virus in Shanghai, China in 2013. Biosci Trends (2015) 9:73-8. doi:10.5582/bst.2014.01113

47. Mauad T, Hajjar LA, Callegari GD, Da Silva LF, Schout D, Galas FR, et al. Lung pathology in fatal novel human influenza A (H1N1) infection. Am J Respir Crit Care Med (2010) 181:72-9. doi:10.1164/rccm.200909-1420OC

48. To KK, Hung IF, Li IW, Lee KL, Koo CK, Yan WW, et al. Delayed clearance of viral load and marked cytokine activation in severe cases of pandemic H1N1 2009 influenza virus infection. Clin Infect Dis (2010) 50:850-9. doi:10.1086/ 650581

49. Taubenberger JK, Morens DM. The pathology of influenza virus infections. Annu Rev Pathol (2008) 3:499-522. doi:10.1146/annurev.pathmechdis. 3.121806 .154316

50. Guarner J, Falcon-Escobedo R. Comparison of the pathology caused by H1N1, H5N1, and H3N2 influenza viruses. Arch Med Res (2009) 40:655-61. doi:10. 1016/j.arcmed.2009.10.001

51. Yu L, Wang Z, Chen Y, Ding W, Jia H, Chan JF, et al. Clinical, virological, and histopathological manifestations of fatal human infections by avian influenza A(H7N9) virus. Clin Infect Dis (2013) 57:1449-57. doi:10.1093/cid/cit541

52. Gao R, Bhatnagar J, Blau DM, Greer P, Rollin DC, Denison AM, et al. Cytokine and chemokine profiles in lung tissues from fatal cases of 2009 pandemic influenza A (H1N1): role of the host immune response in pathogenesis. Am J Pathol (2013) 183:1258-68. doi:10.1016/j.ajpath.2013.06.023

53. Bermejo-Martin JF, Ortiz De Lejarazu R, Pumarola T, Rello J, Almansa R, Ramirez P, et al. Th1 and Th17 hypercytokinemia as early host response signature in severe pandemic influenza. Crit Care (2009) 13:R201. doi:10.1186/ cc8208

54. Tiwari N, Kapoor P, Dhole TN. Antibody and inflammatory responsemediated severity of pandemic 2009 (pH1N1) influenza virus. J Med Virol (2014) 86:1034-40. doi:10.1002/jmv.23877

55. Chiaretti A, Pulitano S, Barone G, Ferrara P, Romano V, Capozzi D, et al. IL-1 beta and IL-6 upregulation in children with H1N1 influenza virus infection. Mediators Inflamm (2013) 2013:495848. doi:10.1155/2013/495848

56. Yu X, Zhang X, Zhao B, Wang J, Zhu Z, Teng Z, et al. Intensive cytokine induction in pandemic H1N1 influenza virus infection accompanied by robust production of IL-10 and IL-6. PLoS One (2011) 6:e28680. doi:10.1371/journal. pone. 0028680

57. Hagau N, Slavcovici A, Gonganau DN, Oltean S, Dirzu DS, Brezoszki ES, et al. Clinical aspects and cytokine response in severe $\mathrm{H} 1 \mathrm{~N} 1$ influenza A virus infection. Crit Care (2010) 14:R203. doi:10.1186/cc9324

58. Bian JR, Nie W, Zang YS, Fang Z, Xiu QY, Xu XX. Clinical aspects and cytokine response in adults with seasonal influenza infection. Int J Clin Exp Med (2014) 7:5593-602.
59. Peiris JS, Yu WC, Leung CW, Cheung CY, Ng WF, Nicholls JM, et al. Reemergence of fatal human influenza A subtype H5N1 disease. Lancet (2004) 363:617-9. doi:10.1016/S0140-6736(04)15595-5

60. de Jong MD, Simmons CP, Thanh TT, Hien VM, Smith GJ, Chau TN, et al. Fatal outcome of human influenza A (H5N1) is associated with high viral load and hypercytokinemia. Nat Med (2006) 12:1203-7. doi:10.1038/ nm1477

61. Deng R, Lu M, Korteweg C, Gao Z, Mcnutt MA, Ye J, et al. Distinctly different expression of cytokines and chemokines in the lungs of two H5N1 avian influenza patients. J Pathol (2008) 216:328-36. doi:10.1002/path.2417

62. Wang Z, Zhang A, Wan Y, Liu X, Qiu C, Xi X, et al. Early hypercytokinemia is associated with interferon-induced transmembrane protein-3 dysfunction and predictive of fatal H7N9 infection. Proc Natl Acad Sci U S A (2014) 111:769-74. doi:10.1073/pnas.1321748111

63. Shen Z, Chen Z, Li X, Xu L, Guan W, Cao Y, et al. Host immunological response and factors associated with clinical outcome in patients with the novel influenza A H7N9 infection. Clin Microbiol Infect (2014) 20:O493-500. doi:10.1111/1469-0691.12505

64. Ramos I, Bernal-Rubio D, Durham N, Belicha-Villanueva A, Lowen AC, Steel $\mathrm{J}$, et al. Effects of receptor binding specificity of avian influenza virus on the human innate immune response. J Virol (2011) 85:4421-31. doi:10.1128/JVI. 02356-10

65. Kim KS, Jung H, Shin IK, Choi BR, Kim DH. Induction of interleukin-1 beta (IL-1beta) is a critical component of lung inflammation during influenza A (H1N1) virus infection. J Med Virol (2015) 87(7):1104-12. doi:10.1002/jmv. 24138

66. Venkatesha SH, Dudics S, Acharya B, Moudgil KD. Cytokine-modulating strategies and newer cytokine targets for arthritis therapy. Int J Mol Sci (2015) 16:887-906. doi:10.3390/ijms16010887

67. Wajant H, Pfizenmaier K, Scheurich P. Tumor necrosis factor signaling. Cell Death Differ (2003) 10:45-65. doi:10.1038/sj.cdd.4401189

68. Sethu S, Melendez AJ. New developments on the TNFalpha-mediated signalling pathways. Biosci Rep (2011) 31:63-76. doi:10.1042/BSR20100040

69. Chen G, Goeddel DV. TNF-R1 signaling: a beautiful pathway. Science (2002) 296:1634-5. doi:10.1126/science.1071924

70. Ghosh S, Karin M. Missing pieces in the NF-kappaB puzzle. Cell (2002) 109(Suppl):S81-96. doi:10.1016/S0092-8674(02)00703-1

71. Karin M, Lawrence T, Nizet V. Innate immunity gone awry: linking microbial infections to chronic inflammation and cancer. Cell (2006) 124:823-35. doi:10. 1016/j.cell.2006.02.016

72. Thorburn A. Death receptor-induced cell killing. Cell Signal (2004) 16:139-44. doi:10.1016/j.cellsig.2003.08.007

73. Lin Y, Choksi S, Shen HM, Yang QF, Hur GM, Kim YS, et al. Tumor necrosis factor-induced nonapoptotic cell death requires receptor-interacting proteinmediated cellular reactive oxygen species accumulation. J Biol Chem (2004) 279:10822-8. doi:10.1074/jbc.M313141200

74. Morgan MJ, Kim YS, Liu ZG. TNFalpha and reactive oxygen species in necrotic cell death. Cell Res (2008) 18:343-9. doi:10.1038/cr.2008.31

75. Pasparakis M, Vandenabeele P. Necroptosis and its role in inflammation. Nature (2015) 517:311-20. doi:10.1038/nature14191

76. Morgan MJ, Liu ZG. Reactive oxygen species in TNFalpha-induced signaling and cell death. Mol Cells (2010) 30:1-12. doi:10.1007/s10059-010-0105-0

77. Newburger PE, Dai Q, Whitney C. In vitro regulation of human phagocyte cytochrome b heavy and light chain gene expression by bacterial lipopolysaccharide and recombinant human cytokines. J Biol Chem (1991) 266:16171-7.

78. Moe KT, Aulia S, Jiang F, Chua YL, Koh TH, Wong MC, et al. Differential upregulation of Nox homologues of NADPH oxidase by tumor necrosis factoralpha in human aortic smooth muscle and embryonic kidney cells. J Cell Mol Med (2006) 10:231-9. doi:10.1111/j.1582-4934.2006.tb00304.x

79. Muller M, Althaus R, Frohlich D, Frei K, Eugster HP. Reduced antilisterial activity of TNF-deficient bone marrow-derived macrophages is due to impaired superoxide production. Eur J Immunol (1999) 29:3089-97. doi:10. 1002/(SICI)1521-4141(199910)29:10<3089::AID-IMMU3089>3.0.CO;2-D

80. Karampetsou MP, Liossis SN, Sfikakis PP. TNF-alpha antagonists beyond approved indications: stories of success and prospects for the future. $Q J M$ (2010) 103:917-28. doi:10.1093/qjmed/hcq152 
81. Shi X, Zhou W, Huang H, Zhu H, Zhou P, Zhu H, et al. Inhibition of the inflammatory cytokine tumor necrosis factor-alpha with etanercept provides protection against lethal H1N1 influenza infection in mice. Crit Care (2013) 17:R301. doi:10.1186/cc13171

82. Xing Z, Gauldie J, Cox G, Baumann H, Jordana M, Lei XF, et al. IL-6 is an antiinflammatory cytokine required for controlling local or systemic acute inflammatory responses. J Clin Invest (1998) 101:311-20. doi:10.1172/JCI1368

83. Scheller J, Chalaris A, Schmidt-Arras D, Rose-John S. The pro- and antiinflammatory properties of the cytokine interleukin-6. Biochim Biophys Acta (2011) 1813:878-88. doi:10.1016/j.bbamcr.2011.01.034

84. Tanaka T, Kishimoto T. The biology and medical implications of interleukin-6. Cancer Immunol Res (2014) 2:288-94. doi:10.1158/2326-6066.CIR-14-0022

85. Scheller J, Garbers C, Rose-John S. Interleukin-6: from basic biology to selective blockade of pro-inflammatory activities. Semin Immunol (2014) 26:2-12. doi:10.1016/j.smim.2013.11.002

86. Heinrich PC, Behrmann I, Haan S, Hermanns HM, Muller-Newen G, Schaper F. Principles of interleukin (IL)-6-type cytokine signalling and its regulation. Biochem J (2003) 374:1-20. doi:10.1042/BJ20030407

87. Hsu JH, Shi Y, Frost P, Yan H, Hoang B, Sharma S, et al. Interleukin-6 activates phosphoinositol- $3^{\prime}$ kinase in multiple myeloma tumor cells by signaling through RAS-dependent and, separately, through p85-dependent pathways. Oncogene (2004) 23:3368-75. doi:10.1038/sj.onc.1207459

88. Perlmutter DH, Dinarello CA, Punsal PI, Colten HR. Cachectin/tumor necrosis factor regulates hepatic acute-phase gene expression. J Clin Invest (1986) 78:1349-54. doi:10.1172/JCI112721

89. Gauldie J, Richards C, Harnish D, Lansdorp P, Baumann H. Interferon beta 2/B-cell stimulatory factor type 2 shares identity with monocyte-derived hepatocyte-stimulating factor and regulates the major acute phase protein response in liver cells. Proc Natl Acad Sci U S A (1987) 84:7251-5. doi:10.1073/ pnas.84.20.7251

90. Jain S, Gautam V, Naseem S. Acute-phase proteins: as diagnostic tool. J Pharm Bioallied Sci (2011) 3:118-27. doi:10.4103/0975-7406.76489

91. Agassandian M, Shurin GV, Ma Y, Shurin MR. C-reactive protein and lung diseases. Int J Biochem Cell Biol (2014) 53:77-88. doi:10.1016/j.biocel. 2014.05.016

92. Zimmerman O, Rogowski O, Aviram G, Mizrahi M, Zeltser D, Justo D, et al. Creactive protein serum levels as an early predictor of outcome in patients with pandemic H1N1 influenza A virus infection. BMC Infect Dis (2010) 10:288. doi:10.1186/1471-2334-10-288

93. Bajwa EK, Khan UA, Januzzi JL, Gong MN, Thompson BT, Christiani DC. Plasma C-reactive protein levels are associated with improved outcome in ARDS. Chest (2009) 136:471-80. doi:10.1378/chest.08-2413

94. Kang S, Tanaka T, Kishimoto T. Therapeutic uses of anti-interleukin-6 receptor antibody. Int Immunol (2015) 27:21-9. doi:10.1093/intimm/dxu081

95. Lauder SN, Jones E, Smart K, Bloom A, Williams AS, Hindley JP, et al. Interleukin-6 limits influenza-induced inflammation and protects against fatal lung pathology. Eur J Immunol (2013) 43:2613-25. doi:10.1002/eji.201243018

96. Dinarello CA. Interleukin-1 in the pathogenesis and treatment of inflammatory diseases. Blood (2011) 117:3720-32. doi:10.1182/blood-2010-07-273417

97. Flannery S, Bowie AG. The interleukin-1 receptor-associated kinases: critical regulators of innate immune signalling. Biochem Pharmacol (2010) 80:1981-91. doi:10.1016/j.bcp.2010.06.020

98. Weber A, Wasiliew P, Kracht M. Interleukin-1 (IL-1) pathway. Sci Signal (2010) 3:cm1. doi:10.1126/scisignal.3105 $\mathrm{cm} 1$

99. Wang X, Feuerstein GZ, Gu JL, Lysko PG, Yue TL. Interleukin-1 beta induces expression of adhesion molecules in human vascular smooth muscle cells and enhances adhesion of leukocytes to smooth muscle cells. Atherosclerosis (1995) 115:89-98. doi:10.1016/0021-9150(94)05503-B

100. Dinarello CA, Simon A, Van Der Meer JW. Treating inflammation by blocking interleukin-1 in a broad spectrum of diseases. Nat Rev Drug Discov (2012) 11:633-52. doi:10.1038/nrd3800

101. Dinarello CA. The IL-1 family and inflammatory diseases. Clin Exp Rheumatol (2002) 20:S1-13.

102. McAuley JL, Tate MD, Mackenzie-Kludas CJ, Pinar A, Zeng W, Stutz A, et al. Activation of the NLRP3 inflammasome by IAV virulence protein PB1F2 contributes to severe pathophysiology and disease. PLoS Pathog (2013) 9:e1003392. doi:10.1371/journal.ppat.1003392

103. Swiergiel AH, Smagin GN, Johnson LJ, Dunn AJ. The role of cytokines in the behavioral responses to endotoxin and influenza virus infection in mice: effects of acute and chronic administration of the interleukin-1-receptor antagonist (IL-1ra). Brain Res (1997) 776:96-104. doi:10.1016/S0006-8993(97)01009-3

104. Kozak W, Zheng H, Conn CA, Soszynski D, Van Der Ploeg LH, Kluger MJ. Thermal and behavioral effects of lipopolysaccharide and influenza in interleukin-1 beta-deficient mice. Am J Physiol (1995) 269:R969-77.

105. Thomas PG, Dash P, Aldridge JR Jr, Ellebedy AH, Reynolds C, Funk AJ, et al. The intracellular sensor NLRP3 mediates key innate and healing responses to influenza A virus via the regulation of caspase-1. Immunity (2009) 30:566-75. doi:10.1016/j.immuni.2009.02.006

106. Geiser T, Atabai K, Jarreau PH, Ware LB, Pugin J, Matthay MA. Pulmonary edema fluid from patients with acute lung injury augments in vitro alveolar epithelial repair by an IL-1beta-dependent mechanism. Am J Respir Crit Care Med (2001) 163:1384-8. doi:10.1164/ajrccm.163.6.2006131

107. Geiser T. Mechanisms of alveolar epithelial repair in acute lung injury - a translational approach. Swiss Med Wkly (2003) 133:586-90.

108. Thickett DR, Perkins GD. IL1 may be elevated but is it all bad in ARDS? Thorax (2008) 63:750-1.

109. Geiser T, Jarreau PH, Atabai K, Matthay MA. Interleukin-1beta augments in vitro alveolar epithelial repair. Am J Physiol Lung Cell Mol Physiol (2000) 279:L1184-90.

110. Sanchez-Guerrero E, Chen E, Kockx M, An SW, Chong BH, Khachigian LM. IL-1beta signals through the EGF receptor and activates Egr-1 through MMP-ADAM. PLoS One (2012) 7:e39811. doi:10.1371/journal.pone.0039811

111. Levy DE, Marie IJ, Durbin JE. Induction and function of type I and III interferon in response to viral infection. Curr Opin Virol (2011) 1:476-86. doi:10.1016/j.coviro.2011.11.001

112. Schreiber G, Piehler J. The molecular basis for functional plasticity in type I interferon signaling. Trends Immunol (2015) 36:139-49. doi:10.1016/j.it.2015. 01.002

113. Levy DE, Darnell JE Jr. Stats: transcriptional control and biological impact. Nat Rev Mol Cell Biol (2002) 3:651-62. doi:10.1038/nrm909

114. Knight E Jr, Korant BD. Fibroblast interferon induces synthesis of four proteins in human fibroblast cells. Proc Natl Acad Sci U S A (1979) 76:1824-7. doi:10. 1073/pnas.76.4.1824

115. Ivashkiv LB, Donlin LT. Regulation of type I interferon responses. Nat Rev Immunol (2014) 14:36-49. doi:10.1038/nri3581

116. Wesoly J, Szweykowska-Kulinska Z, Bluyssen HA. STAT activation and differential complex formation dictate selectivity of interferon responses. Acta Biochim Pol (2007) 54:27-38.

117. Ho HH, Ivashkiv LB. Role of STAT3 in type I interferon responses. Negative regulation of STAT1-dependent inflammatory gene activation. J Biol Chem (2006) 281:14111-8. doi:10.1074/jbc.M511797200

118. Kotenko SV, Gallagher G, Baurin VV, Lewis-Antes A, Shen M, Shah NK, et al. IFN-lambdas mediate antiviral protection through a distinct class II cytokine receptor complex. Nat Immunol (2003) 4:69-77. doi:10.1038/ni875

119. Sheppard P, Kindsvogel W, Xu W, Henderson K, Schlutsmeyer S, Whitmore TE, et al. IL-28, IL-29 and their class II cytokine receptor IL-28R. Nat Immunol (2003) 4:63-8. doi:10.1038/ni873

120. Iversen MB, Paludan SR. Mechanisms of type III interferon expression. J Interferon Cytokine Res (2010) 30:573-8. doi:10.1089/jir.2010.0063

121. Muller U, Steinhoff U, Reis LF, Hemmi S, Pavlovic J, Zinkernagel RM, et al. Functional role of type I and type II interferons in antiviral defense. Science (1994) 264:1918-21. doi:10.1126/science.8009221

122. Decker T, Muller M, Stockinger S. The yin and yang of type I interferon activity in bacterial infection. Nat Rev Immunol (2005) 5:675-87. doi:10.1038/ nri1684

123. Davidson S, Crotta S, Mccabe TM, Wack A. Pathogenic potential of interferon alphabeta in acute influenza infection. Nat Commun (2014) 5:3864. doi:10. $1038 /$ ncomms 4864

124. Crow MK. Type I interferon in the pathogenesis of lupus. J Immunol (2014) 192:5459-68. doi:10.4049/jimmunol.1002795

125. Rodriguez-Carrio J, Lopez P, Suarez A. Type I IFNs as biomarkers in rheumatoid arthritis: towards disease profiling and personalized medicine. Clin Sci (Lond) (2015) 128:449-64. doi:10.1042/CS20140554

126. Rice GI, Forte GM, Szynkiewicz M, Chase DS, Aeby A, Abdel-Hamid MS, et al. Assessment of interferon-related biomarkers in Aicardi-Goutieres syndrome associated with mutations in TREX1, RNASEH2A, RNASEH2B, RNASEH2C, SAMHD1, and ADAR: a case-control study. Lancet Neurol (2013) 12:1159-69. doi:10.1016/S1474-4422(13)70258-8 
127. Stockinger S, Materna T, Stoiber D, Bayr L, Steinborn R, Kolbe T, et al. Production of type I IFN sensitizes macrophages to cell death induced by Listeria monocytogenes. J Immunol (2002) 169:6522-9. doi:10.4049/jimmunol. 169.11.6522

128. Jones Buie JN, Oates JC. Role of interferon alpha in endothelial dysfunction: insights into endothelial nitric oxide synthase-related mechanisms. Am J Med Sci (2014) 348:168-75. doi:10.1097/MAJ.0000000000000284

129. Mordstein M, Kochs G, Dumoutier L, Renauld JC, Paludan SR, Klucher K, et al. Interferon-lambda contributes to innate immunity of mice against influenza A virus but not against hepatotropic viruses. PLoS Pathog (2008) 4:e1000151. doi:10.1371/journal.ppat.1000151

130. Schroder K, Hertzog PJ, Ravasi T, Hume DA. Interferon-gamma: an overview of signals, mechanisms and functions. J Leukoc Biol (2004) 75:163-89. doi:10. 1189/jlb.0603252

131. Pestka S, Kotenko SV, Muthukumaran G, Izotova LS, Cook JR, Garotta G. The interferon gamma (IFN-gamma) receptor: a paradigm for the multichain cytokine receptor. Cytokine Growth Factor Rev (1997) 8:189-206. doi:10.1016/ S1359-6101(97)00009-9

132. Fujimaki H, Hikawa N, Nagoya M, Nagata T, Minami M. IFN-gamma induces expression of MHC class I molecules in adult mouse dorsal root ganglion neurones. Neuroreport (1996) 7:2951-5. doi:10.1097/00001756-199611250-00030

133. Rosa FM, Fellous M. Regulation of HLA-DR gene by IFN-gamma. Transcriptional and post-transcriptional control. J Immunol (1988) 140:1660-4.

134. Aki M, Shimbara N, Takashina M, Akiyama K, Kagawa S, Tamura T, et al. Interferon-gamma induces different subunit organizations and functional diversity of proteasomes. J Biochem (1994) 115:257-69.

135. Fruh K, Yang Y. Antigen presentation by MHC class I and its regulation by interferon gamma. Curr Opin Immunol (1999) 11:76-81. doi:10.1016/ S0952-7915(99)80014-4

136. Kloetzel PM, Ossendorp F. Proteasome and peptidase function in MHCclass-I-mediated antigen presentation. Curr Opin Immunol (2004) 16:76-81. doi:10.1016/j.coi.2003.11.004

137. Kowanko IC, Ferrante A. Stimulation of neutrophil respiratory burst and lysosomal enzyme release by human interferon-gamma. Immunology (1987) 62:149-51.

138. Ellis TN, Beaman BL. Interferon-gamma activation of polymorphonuclear neutrophil function. Immunology (2004) 112:2-12. doi:10.1111/j.1365-2567. 2004.01849.x

139. Reshi ML, Su YC, Hong JR. RNA viruses: ROS-mediated cell death. Int J Cell Biol (2014) 2014:467452. doi:10.1155/2014/467452

140. Lee JY, Goldman D, Piliero LM, Petri M, Sullivan KE. Interferon-gamma polymorphisms in systemic lupus erythematosus. Genes Immun (2001) 2:254-7. doi:10.1038/sj.gene.6363775

141. Panitch HS, Hirsch RL, Haley AS, Johnson KP. Exacerbations of multiple sclerosis in patients treated with gamma interferon. Lancet (1987) 1:893-5. doi:10.1016/S0140-6736(87)92863-7

142. Bruserud O, Kittang AO. The chemokine system in experimental and clinical hematology. Curr Top Microbiol Immunol (2010) 341:3-12. doi:10.1007/82 2010_18

143. Schall TJ, Jongstra J, Dyer BJ, Jorgensen J, Clayberger C, Davis MM, et al. A human T cell-specific molecule is a member of a new gene family. J Immunol (1988) 141:1018-25.

144. Maghazachi AA, Al-Aoukaty A, Schall TJ. C-C chemokines induce the chemotaxis of NK and IL-2-activated NK cells. Role for G proteins. J Immunol (1994) 153:4969-77.

145. Keophiphath M, Rouault C, Divoux A, Clement K, Lacasa D. CCL5 promotes macrophage recruitment and survival in human adipose tissue. Arterioscler Thromb Vasc Biol (2010) 30:39-45. doi:10.1161/ATVBAHA.109.197442

146. Marques RE, Guabiraba R, Russo RC, Teixeira MM. Targeting CCL5 in inflammation. Expert Opin Ther Targets (2013) 17:1439-60. doi:10.1517/14728222. 2013.837886

147. Alkhatib G, Combadiere C, Broder CC, Feng Y, Kennedy PE, Murphy PM, et al. CC CKR5: a RANTES, MIP-1alpha, MIP-1beta receptor as a fusion cofactor for macrophage-tropic HIV-1. Science (1996) 272:1955-8. doi:10. 1126/science.272.5270.1955

148. Fatkenheuer G, Pozniak AL, Johnson MA, Plettenberg A, Staszewski S, Hoepelman AI, et al. Efficacy of short-term monotherapy with maraviroc, a new CCR5 antagonist, in patients infected with HIV-1. Nat Med (2005) 11:1170-2. doi: $10.1038 / \mathrm{nm} 1319$
149. Jones KL, Maguire JJ, Davenport AP. Chemokine receptor CCR5: from AIDS to atherosclerosis. Br J Pharmacol (2011) 162:1453-69. doi:10.1111/j. 1476-5381.2010.01147.x

150. Korteweg C, Gu J. Pathology, molecular biology, and pathogenesis of avian influenza A (H5N1) infection in humans. Am J Pathol (2008) 172:1155-70. doi:10.2353/ajpath.2008.070791

151. Dawson TC, Beck MA, Kuziel WA, Henderson F, Maeda N. Contrasting effects of CCR5 and CCR2 deficiency in the pulmonary inflammatory response to influenza A virus. Am J Pathol (2000) 156:1951-9. doi:10.1016/ S0002-9440(10)65068-7

152. Majumder S, Zhou LZ, Chaturvedi P, Babcock G, Aras S, Ransohoff RM. Regulation of human IP-10 gene expression in astrocytoma cells by inflammatory cytokines. J Neurosci Res (1998) 54:169-80. doi:10.1002/(SICI) 1097-4547(19981015)54:2<169::AID-JNR5>3.0.CO;2-C

153. Brownell J, Bruckner J, Wagoner J, Thomas E, Loo YM, Gale M Jr, et al. Direct, interferon-independent activation of the CXCL10 promoter by NF-kappaB and interferon regulatory factor 3 during hepatitis $\mathrm{C}$ virus infection. $J$ Virol (2014) 88:1582-90. doi:10.1128/JVI.02007-13

154. Liu M, Guo S, Hibbert JM, Jain V, Singh N, Wilson NO, et al. CXCL10/IP10 in infectious diseases pathogenesis and potential therapeutic implications. Cytokine Growth Factor Rev (2011) 22:121-30. doi:10.1016/j.cytogfr. 2011.06.001

155. Antonelli A, Ferrari SM, Giuggioli D, Ferrannini E, Ferri C, Fallahi P. Chemokine (C-X-C motif) ligand (CXCL) 10 in autoimmune diseases. Autoimmun Rev (2014) 13:272-80. doi:10.1016/j.autrev.2013.10.010

156. Ichikawa A, Kuba K, Morita M, Chida S, Tezuka H, Hara H, et al. CXCL10CXCR3 enhances the development of neutrophil-mediated fulminant lung injury of viral and nonviral origin. Am J Respir Crit Care Med (2013) 187:65-77. doi:10.1164/rccm.201203-0508OC

157. Gales D, Clark C, Manne U, Samuel T. The chemokine CXCL8 in carcinogenesis and drug response. ISRN Oncol (2013) 2013:859154. doi:10.1155/2013/ 859154

158. Julkunen I, Melen K, Nyqvist M, Pirhonen J, Sareneva T, Matikainen S. Inflammatory responses in influenza A virus infection. Vaccine (2000) 19(Suppl 1):S32-7. doi:10.1016/S0264-410X(00)00275-9

159. Matsukura S, Kokubu F, Noda H, Tokunaga H, Adachi M. Expression of IL-6, IL-8, and RANTES on human bronchial epithelial cells, NCI-H292, induced by influenza virus A. J Allergy Clin Immunol (1996) 98:1080-7. doi:10.1016/ S0091-6749(96)80195-3

160. Casola A, Garofalo RP, Jamaluddin M, Vlahopoulos S, Brasier AR. Requirement of a novel upstream response element in respiratory syncytial virusinduced IL-8 gene expression. J Immunol (2000) 164:5944-51. doi:10.4049/ jimmunol.164.11.5944

161. Wagoner J, Austin M, Green J, Imaizumi T, Casola A, Brasier A, et al. Regulation of CXCL-8 (interleukin-8) induction by double-stranded RNA signaling pathways during hepatitis C virus infection. J Virol (2007) 81:309-18. doi:10.1128/JVI.01411-06

162. Vogel AJ, Harris S, Marsteller N, Condon SA, Brown DM. Early cytokine dysregulation and viral replication are associated with mortality during lethal influenza infection. Viral Immunol (2014) 27:214-24. doi:10.1089/vim. 2013.0095

163. Williams AE, Chambers RC. The mercurial nature of neutrophils: still an enigma in ARDS? Am J Physiol Lung Cell Mol Physiol (2014) 306:L217-30. doi:10.1152/ajplung.00311.2013

164. Kurdowska A, Noble JM, Steinberg KP, Ruzinski JT, Hudson LD, Martin TR. Anti-interleukin 8 autoantibody: interleukin 8 complexes in the acute respiratory distress syndrome. Relationship between the complexes and clinical disease activity. Am J Respir Crit Care Med (2001) 163:463-8. doi:10.1164/ ajrccm.163.2.2005109

165. Gu L, Tseng S, Horner RM, Tam C, Loda M, Rollins BJ. Control of TH2 polarization by the chemokine monocyte chemoattractant protein-1. Nature (2000) 404:407-11. doi:10.1038/35006097

166. Panganiban RP, Vonakis BM, Ishmael FT, Stellato C. Coordinated post-transcriptional regulation of the chemokine system: messages from CCL2. J Interferon Cytokine Res (2014) 34:255-66. doi:10.1089/jir. 2013.0149

167. Deshmane SL, Kremlev S, Amini S, Sawaya BE. Monocyte chemoattractant protein-1 (MCP-1): an overview. I Interferon Cytokine Res (2009) 29:313-26. doi:10.1089/jir.2008.0027 
168. Rose CE Jr, Sung SS, Fu SM. Significant involvement of CCL2 (MCP-1) in inflammatory disorders of the lung. Microcirculation (2003) 10:273-88. doi:10. 1038/sj.mn.7800193

169. Daly C, Rollins BJ. Monocyte chemoattractant protein-1 (CCL2) in inflammatory disease and adaptive immunity: therapeutic opportunities and controversies. Microcirculation (2003) 10:247-57. doi:10.1080/713773639

170. Semple BD, Kossmann T, Morganti-Kossmann MC. Role of chemokines in CNS health and pathology: a focus on the CCL2/CCR2 and CXCL8/CXCR2 networks. J Cereb Blood Flow Metab (2010) 30:459-73. doi:10.1038/jcbfm. 2009.240

171. Wain JH, Kirby JA, Ali S. Leucocyte chemotaxis: examination of mitogenactivated protein kinase and phosphoinositide 3-kinase activation by monocyte chemoattractant proteins-1, -2, -3 and -4. Clin Exp Immunol (2002) 127:436-44. doi:10.1046/j.1365-2249.2002.01764.x

172. Stamatovic SM, Shakui P, Keep RF, Moore BB, Kunkel SL, Van Rooijen N, et al. Monocyte chemoattractant protein-1 regulation of blood-brain barrier permeability. J Cereb Blood Flow Metab (2005) 25:593-606. doi:10.1038/sj. jcbfm.9600055

173. Damjanovic D, Divangahi M, Kugathasan K, Small CL, Zganiacz A, Brown EG, et al. Negative regulation of lung inflammation and immunopathology by TNF-alpha during acute influenza infection. Am J Pathol (2011) 179:2963-76. doi:10.1016/j.ajpath.2011.09.003

174. Narasaraju T, Ng HH, Phoon MC, Chow VT. MCP-1 antibody treatment enhances damage and impedes repair of the alveolar epithelium in influenza pneumonitis. Am J Respir Cell Mol Biol (2010) 42:732-43. doi:10.1165/rcmb. 2008-0423OC

175. Menten P, Wuyts A, Van Damme J. Macrophage inflammatory protein-1. Cytokine Growth Factor Rev (2002) 13:455-81. doi:10.1016/S1359-6101(02) 00045-X

176. Tanaka Y, Adams DH, Hubscher S, Hirano H, Siebenlist U, Shaw S. T-cell adhesion induced by proteoglycan-immobilized cytokine MIP-1 beta. Nature (1993) 361:79-82. doi:10.1038/361079a0

177. Guan E, Wang J, Roderiquez G, Norcross MA. Natural truncation of the chemokine MIP-1 beta/CCL4 affects receptor specificity but not antiHIV-1 activity. J Biol Chem (2002) 277:32348-52. doi:10.1074/jbc.M203 077200

178. Vila LM, Molina MJ, Mayor AM, Cruz JJ, Rios-Olivares E, Rios Z. Association of serum MIP-1alpha, MIP-1beta, and RANTES with clinical manifestations, disease activity, and damage accrual in systemic lupus erythematosus. Clin Rheumatol (2007) 26:718-22. doi:10.1007/s10067-006-0387-y

179. Tang BM, Craig JC, Eslick GD, Seppelt I, Mclean AS. Use of corticosteroids in acute lung injury and acute respiratory distress syndrome: a systematic review and meta-analysis. Crit Care Med (2009) 37:1594-603. doi:10.1097/ CCM.0b013e31819fb507

180. Beigel JH, Farrar J, Han AM, Hayden FG, Hyer R, de Jong MD, et al. Avian influenza A (H5N1) infection in humans. N Engl J Med (2005) 353:1374-85. doi:10.1056/NEJMra052211

181. Quispe-Laime AM, Bracco JD, Barberio PA, Campagne CG, Rolfo VE, Umberger R, et al. H1N1 influenza A virus-associated acute lung injury: response to combination oseltamivir and prolonged corticosteroid treatment. Intensive Care Med (2010) 36:33-41. doi:10.1007/s00134-009-1727-6

182. Hui DS, Lee N. Adjunctive therapies and immunomodulating agents for severe influenza. Influenza Other Respir Viruses (2013) 7(Suppl 3):52-9. doi:10.1111/ irv. 12171

183. Kudo K, Takasaki J, Manabe T, Uryu H, Yamada R, Kuroda E, et al. Systemic corticosteroids and early administration of antiviral agents for pneumonia with acute wheezing due to influenza $\mathrm{A}(\mathrm{H} 1 \mathrm{~N} 1) \mathrm{pdm} 09$ in Japan. PLoS One (2012) 7:e32280. doi:10.1371/journal.pone.0032280

184. Lee N, Chan PK, Hui DS, Rainer TH, Wong E, Choi KW, et al. Viral loads and duration of viral shedding in adult patients hospitalized with influenza. J Infect Dis (2009) 200:492-500. doi:10.1086/600383

185. Kim SH, Hong SB, Yun SC, Choi WI, Ahn JJ, Lee YJ, et al. Corticosteroid treatment in critically ill patients with pandemic influenza A/H1N1 2009 infection: analytic strategy using propensity scores. Am J Respir Crit Care Med (2011) 183:1207-14. doi:10.1164/rccm.201101-0110OC

186. Thomas BJ, Porritt RA, Hertzog PJ, Bardin PG, Tate MD. Glucocorticosteroids enhance replication of respiratory viruses: effect of adjuvant interferon. Sci Rep (2014) 4:7176. doi:10.1038/srep07176
187. Zhang Y, Sun W, Svendsen ER, Tang S, Macintyre RC, Yang P, et al. Do corticosteroids reduce the mortality of influenza A (H1N1) infection? A meta-analysis. Crit Care (2015) 19:46. doi:10.1186/s13054-015-0764-5

188. Shodell M, Siegal FP. Corticosteroids depress IFN-alpha-producing plasmacytoid dendritic cells in human blood. J Allergy Clin Immunol (2001) 108:446-8. doi:10.1067/mai.2001.117928

189. WHO. WHO Guidelines for Pharmacological Management of Pandemic (H1N1) 2009: Influenza and Other Influenza Viruses. Geneva: World Health Organization (2009).

190. Pruefer D, Makowski J, Schnell M, Buerke U, Dahm M, Oelert H, et al. Simvastatin inhibits inflammatory properties of Staphylococcus aureus alphatoxin. Circulation (2002) 106:2104-10. doi:10.1161/01.CIR.0000034048. 38910.91

191. Mehrbod P, Omar AR, Hair-Bejo M, Haghani A, Ideris A. Mechanisms of action and efficacy of statins against influenza. Biomed Res Int (2014) 2014:872370. doi:10.1155/2014/872370

192. Tousoulis D, Psarros C, Demosthenous M, Patel R, Antoniades C, Stefanadis C. Innate and adaptive inflammation as a therapeutic target in vascular disease: the emerging role of statins. J Am Coll Cardiol (2014) 63:2491-502. doi:10. 1016/j.jacc.2014.01.054

193. Vandermeer ML, Thomas AR, Kamimoto L, Reingold A, Gershman K, Meek $\mathrm{J}$, et al. Association between use of statins and mortality among patients hospitalized with laboratory-confirmed influenza virus infections: a multistate study. J Infect Dis (2012) 205:13-9. doi:10.1093/infdis/jir695

194. Frost FJ, Petersen H, Tollestrup K, Skipper B. Influenza and COPD mortality protection as pleiotropic, dose-dependent effects of statins. Chest (2007) 131:1006-12. doi:10.1378/chest.06-1997

195. Carrillo-Esper R, Sosa-Garcia JO, Arch-Tirado E. [Experience in the management of the severe form of human influenza A H1N1 pneumonia in an intensive care unit]. Cir Cir (2011) 79:409-16.

196. Fleming DM, Verlander NQ, Elliot AJ, Zhao H, Gelb D, Jehring D, et al. An assessment of the effect of statin use on the incidence of acute respiratory infections in England during winters 1998-1999 to 2005-2006. Epidemiol Infect (2010) 138:1281-8. doi:10.1017/S0950268810000105

197. Viasus D, Pano-Pardo JR, Cordero E, Campins A, Lopez-Medrano F, Villoslada A, et al. Effect of immunomodulatory therapies in patients with pandemic influenza A (H1N1) 2009 complicated by pneumonia. J Infect (2011) 62:193-9. doi:10.1016/j.jinf.2011.01.014

198. Mehrbod P, Hair-Bejo M, Tengku Ibrahim TA, Omar AR, El Zowalaty M, Ajdari Z, et al. Simvastatin modulates cellular components in influenza A virus-infected cells. Int J Mol Med (2014) 34:61-73. doi:10.3892/ijmm.2014. 1761

199. Liu Z, Guo Z, Wang G, Zhang D, He H, Li G, et al. Evaluation of the efficacy and safety of a statin/caffeine combination against H5N1, H3N2 and H1N1 virus infection in BALB/c mice. Eur J Pharm Sci (2009) 38:215-23. doi:10.1016/j. ejps.2009.07.004

200. Peng J, Zhang D, Ma Y, Wang G, Guo Z, Lu J. Protective effect of fluvastatin on influenza virus infection. Mol Med Rep (2014) 9:2221-6. doi:10.3892/mmr. 2014.2076

201. Hsu BG, Yang FL, Lee RP, Peng TC, Harn HJ, Chen HI. N-acetylcysteine ameliorates lipopolysaccharide-induced organ damage in conscious rats. J Biomed Sci (2004) 11:152-62. doi:10.1007/BF02256558

202. Hsu BG, Lee RP, Yang FL, Harn HJ, Chen HI. Post-treatment with Nacetylcysteine ameliorates endotoxin shock-induced organ damage in conscious rats. Life Sci (2006) 79:2010-6. doi:10.1016/j.lfs.2006.06.040

203. Kao SJ, Wang D, Lin HI, Chen HI. N-acetylcysteine abrogates acute lung injury induced by endotoxin. Clin Exp Pharmacol Physiol (2006) 33:33-40. doi:10.1111/j.1440-1681.2006.04320.x

204. Geiler J, Michaelis M, Naczk P, Leutz A, Langer K, Doerr HW, et al. Nacetyl-L-cysteine (NAC) inhibits virus replication and expression of proinflammatory molecules in A549 cells infected with highly pathogenic H5N1 influenza A virus. Biochem Pharmacol (2010) 79:413-20. doi:10.1016/j.bcp. 2009.08.025

205. Mata M, Morcillo E, Gimeno C, Cortijo J. N-acetyl-L-cysteine (NAC) inhibit mucin synthesis and pro-inflammatory mediators in alveolar type II epithelial cells infected with influenza virus A and B and with respiratory syncytial virus (RSV). Biochem Pharmacol (2011) 82:548-55. doi:10.1016/j. bcp.2011.05.014 
206. Ghezzi P, Ungheri D. Synergistic combination of N-acetylcysteine and ribavirin to protect from lethal influenza viral infection in a mouse model. Int J Immunopathol Pharmacol (2004) 17:99-102.

207. Garigliany MM, Desmecht DJ. N-acetylcysteine lacks universal inhibitory activity against influenza A viruses. J Negat Results Biomed (2011) 10:5. doi:10. 1186/1477-5751-10-5

208. De Flora S, Grassi C, Carati L. Attenuation of influenza-like symptomatology and improvement of cell-mediated immunity with long-term Nacetylcysteine treatment. Eur Respir J (1997) 10:1535-41. doi:10.1183/ 09031936.97.10071535

209. Desaki M, Takizawa H, Ohtoshi T, Kasama T, Kobayashi K, Sunazuka T. Erythromycin suppresses nuclear factor-kappaB and activator protein- 1 activation in human bronchial epithelial cells. Biochem Biophys Res Commun (2000) 267:124-8. doi:10.1006/bbrc.1999.1917

210. Kikuchi T, Hagiwara K, Honda Y, Gomi K, Kobayashi T, Takahashi H, et al. Clarithromycin suppresses lipopolysaccharide-induced interleukin-8 production by human monocytes through AP- 1 and NF-kappa B transcription factors. J Antimicrob Chemother (2002) 49:745-55. doi:10.1093/jac/dkf008

211. Zhao DM, Xue HH, Chida K, Suda T, Oki Y, Kanai M, et al. Effect of erythromycin on ATP-induced intracellular calcium response in A549 cells. Am J Physiol Lung Cell Mol Physiol (2000) 278:L726-36.

212. Kanoh S, Rubin BK. Mechanisms of action and clinical application of macrolides as immunomodulatory medications. Clin Microbiol Rev (2010) 23:590-615. doi:10.1128/CMR.00078-09

213. Miyamoto D, Hasegawa S, Sriwilaijaroen N, Yingsakmongkon S, Hiramatsu $\mathrm{H}$, Takahashi $\mathrm{T}$, et al. Clarithromycin inhibits progeny virus production from human influenza virus-infected host cells. Biol Pharm Bull (2008) 31:217-22. doi:10.1248/bpb.31.217

214. Sugamata R, Sugawara A, Nagao T, Suzuki K, Hirose T, Yamamoto K, et al. Leucomycin A3, a 16-membered macrolide antibiotic, inhibits influenza A virus infection and disease progression. J Antibiot (Tokyo) (2014) 67:213-22. doi:10.1038/ja.2013.132

215. Azuma A, Yamaya M, Kadota J, Mikasa K, Kudoh S; Influenza Practical Treatment Workshop on New Targets of Macrolides. Use of macrolides in the 2009 H1N1 virus infection outbreak: a survey of general practices in Japan. Respir Investig (2013) 51:257-9. doi:10.1016/j.resinv.2013.04.002

216. Higashi F, Kubo H, Yasuda H, Nukiwa T, Yamaya M. Additional treatment with clarithromycin reduces fever duration in patients with influenza. Respir Investig (2014) 52:302-9. doi:10.1016/j.resinv.2014.05.001

217. Ichinohe T, Pang IK, Kumamoto Y, Peaper DR, Ho JH, Murray TS, et al. Microbiota regulates immune defense against respiratory tract influenza A virus infection. Proc Natl Acad Sci U S A (2011) 108:5354-9. doi:10.1073/pnas. 1019378108

218. Abt MC, Osborne LC, Monticelli LA, Doering TA, Alenghat T, Sonnenberg GF, et al. Commensal bacteria calibrate the activation threshold of innate antiviral immunity. Immunity (2012) 37:158-70. doi:10.1016/j.immuni.2012. 04.011

219. Perez-Sala D, Lamas S. Regulation of cyclooxygenase-2 expression by nitric oxide in cells. Antioxid Redox Signal (2001) 3:231-48. doi:10.1089/ 152308601300185197

220. Carey MA, Bradbury JA, Seubert JM, Langenbach R, Zeldin DC, Germolec DR. Contrasting effects of cyclooxygenase-1 (COX-1) and COX-2 deficiency on the host response to influenza A viral infection. J Immunol (2005) 175:6878-84. doi:10.4049/jimmunol.175.10.6878

221. Lee SM, Cheung CY, Nicholls JM, Hui KP, Leung CY, Uiprasertkul M, et al. Hyperinduction of cyclooxygenase-2-mediated proinflammatory cascade: a mechanism for the pathogenesis of avian influenza H5N1 infection. J Infect Dis (2008) 198:525-35. doi:10.1086/590499

222. Lee MY, Cheung CY, Peiris JS. Role of cyclooxygenase-2 in H5N1 viral pathogenesis and the potential use of its inhibitors. Hong Kong Med J (2013) 19(Suppl 4):29-35.

223. Lee SM, Gai WW, Cheung TK, Peiris JS. Antiviral effect of a selective COX2 inhibitor on H5N1 infection in vitro. Antiviral Res (2011) 91:330-4. doi:10. 1016/j.antiviral.2011.07.011

224. Zheng BJ, Chan KW, Lin YP, Zhao GY, Chan C, Zhang HJ, et al. Delayed antiviral plus immunomodulator treatment still reduces mortality in mice infected by high inoculum of influenza A/H5N1 virus. Proc Natl Acad Sci U S A (2008) 105:8091-6. doi:10.1073/pnas.0711942105
225. Eyers S, Weatherall M, Shirtcliffe P, Perrin K, Beasley R. The effect on mortality of antipyretics in the treatment of influenza infection: systematic review and meta-analysis. J R Soc Med (2010) 103:403-11. doi:10.1258/jrsm.2010.090441

226. Rosenson RS, Wright RS, Farkouh M, Plutzky J. Modulating peroxisome proliferator-activated receptors for therapeutic benefit? Biology, clinical experience, and future prospects. Am Heart J (2012) 164:672-80. doi:10.1016/j.ahj. 2012.06.023

227. Moseley CE, Webster RG, Aldridge JR. Peroxisome proliferator-activated receptor and AMP-activated protein kinase agonists protect against lethal influenza virus challenge in mice. Influenza Other Respir Viruses (2010) 4:307-11. doi:10.1111/j.1750-2659.2010.00155.x

228. Budd A, Alleva L, Alsharifi M, Koskinen A, Smythe V, Mullbacher A, et al. Increased survival after gemfibrozil treatment of severe mouse influenza. Antimicrob Agents Chemother (2007) 51:2965-8. doi:10.1128/AAC.00219-07

229. Aldridge JR Jr, Moseley CE, Boltz DA, Negovetich NJ, Reynolds C, Franks $\mathrm{J}$, et al. TNF/iNOS-producing dendritic cells are the necessary evil of lethal influenza virus infection. Proc Natl Acad Sci U S A (2009) 106:5306-11. doi:10. 1073/pnas.0900655106

230. Cloutier A, Marois I, Cloutier D, Verreault C, Cantin AM, Richter MV. The prostanoid 15-deoxy-Delta12,14-prostaglandin-j2 reduces lung inflammation and protects mice against lethal influenza infection. J Infect Dis (2012) 205:621-30. doi:10.1093/infdis/jir804

231. Fedson DS. Treating influenza with statins and other immunomodulatory agents. Antiviral Res (2013) 99:417-35. doi:10.1016/j.antiviral.2013.06.018

232. Marsolais D, Hahm B, Edelmann KH, Walsh KB, Guerrero M, Hatta Y, et al. Local not systemic modulation of dendritic cell S1P receptors in lung blunts virus-specific immune responses to influenza. Mol Pharmacol (2008) 74:896-903. doi:10.1124/mol.108.048769

233. Marsolais D, Hahm B, Walsh KB, Edelmann KH, Mcgavern D, Hatta Y, et al. A critical role for the sphingosine analog AAL-R in dampening the cytokine response during influenza virus infection. Proc Natl Acad Sci U S A (2009) 106:1560-5. doi:10.1073/pnas.0812689106

234. Walsh KB, Teijaro JR, Wilker PR, Jatzek A, Fremgen DM, Das SC, et al. Suppression of cytokine storm with a sphingosine analog provides protection against pathogenic influenza virus. Proc Natl Acad Sci U S A (2011) 108:12018-23. doi:10.1073/pnas.1107024108

235. Walsh KB, Teijaro JR, Rosen H, Oldstone MB. Quelling the storm: utilization of sphingosine-1-phosphate receptor signaling to ameliorate influenza virus-induced cytokine storm. Immunol Res (2011) 51:15-25. doi:10.1007/ s12026-011-8240-z

236. Teijaro JR, Walsh KB, Cahalan S, Fremgen DM, Roberts E, Scott F, et al. Endothelial cells are central orchestrators of cytokine amplification during influenza virus infection. Cell (2011) 146:980-91. doi:10.1016/j.cell.2011. 08.015

237. Teijaro JR, Walsh KB, Rice S, Rosen H, Oldstone MB. Mapping the innate signaling cascade essential for cytokine storm during influenza virus infection. Proc Natl Acad Sci U S A (2014) 111:3799-804. doi:10.1073/pnas.1400593111

238. Teijaro JR, Walsh KB, Long JP, Tordoff KP, Stark GV, Eisfeld AJ, et al. Protection of ferrets from pulmonary injury due to H1N1 2009 influenza virus infection: immunopathology tractable by sphingosine-1-phosphate 1 receptor agonist therapy. Virology (2014) 45(2-453):152-7. doi:10.1016/j.virol. 2014.01.003

239. Roberts E, Guerrero M, Urbano M, Rosen H. Sphingosine 1-phosphate receptor agonists: a patent review (2010-2012). Expert Opin Ther Pat (2013) 23:817-41. doi:10.1517/13543776.2013.783022

240. Honda Z, Ishii S, Shimizu T. Platelet-activating factor receptor. J Biochem (2002) 131:773-9. doi:10.1093/oxfordjournals.jbchem.a003164

241. McCullers JA, Rehg JE. Lethal synergism between influenza virus and Streptococcus pneumoniae: characterization of a mouse model and the role of plateletactivating factor receptor. J Infect Dis (2002) 186:341-50. doi:10.1086/341462

242. Kasperska-Zajac A, Brzoza Z, Rogala B. Platelet-activating factor (PAF): a review of its role in asthma and clinical efficacy of PAF antagonists in the disease therapy. Recent Pat Inflamm Allergy Drug Discov (2008) 2:72-6. doi:10. 2174/187221308783399306

243. Garcia CC, Russo RC, Guabiraba R, Fagundes CT, Polidoro RB, Tavares LP, et al. Platelet-activating factor receptor plays a role in lung injury and death caused by Influenza A in mice. PLoS Pathog (2010) 6:e1001171. doi:10.1371/ journal.ppat.1001171 
244. Vlahos R, Selemidis S. NADPH oxidases as novel pharmacologic targets against influenza A virus infection. Mol Pharmacol (2014) 86:747-59. doi:10. 1124/mol.114.095216

245. Sharma G, Sharma DC, Fen LH, Pathak M, Bethur N, Pendharkar V, et al. Reduction of influenza virus-induced lung inflammation and mortality in animals treated with a phosophodisestrase- 4 inhibitor and a selective serotonin reuptake inhibitor. Emerg Microbes Infect (2013) 2:e54. doi:10.1038/emi. 2013.52

246. Liu KC, Fang JM, Jan JT, Cheng TJ, Wang SY, Yang ST, et al. Enhanced anti-influenza agents conjugated with anti-inflammatory activity. J Med Chem (2012) 55:8493-501. doi:10.1021/jm3009844
Conflict of Interest Statement: The authors declare that the research was conducted in the absence of any commercial or financial relationships that could be construed as a potential conflict of interest.

Copyright (๑) 2015 Ramos and Fernandez-Sesma. This is an open-access article distributed under the terms of the Creative Commons Attribution License (CC BY). The use, distribution or reproduction in other forums is permitted, provided the original author(s) or licensor are credited and that the original publication in this journal is cited, in accordance with accepted academic practice. No use, distribution or reproduction is permitted which does not comply with these terms. 